\title{
Diagnostic criteria, specific mutations, and genetic predisposition in gastrointestinal stromal tumors
}

This article was published in the following Dove Press journal:

The Application of Clinical Genetics

28 October 2010

Number of times this article has been viewed

\author{
Jean-Baptiste Bachet ${ }^{1,2}$ \\ Jean-François Emile ${ }^{1,3}$ \\ 'EA4340 “Epidémiologie et \\ oncogènes des tumeurs digestives", \\ Faculté de Médecine PIFO, UVSQ, \\ Guyancourt, France; ${ }^{2}$ Service de \\ Gastroentérologie et Oncologie \\ Digestive, Hôpital Ambroise Paré, \\ APHP, Boulogne, France; ${ }^{3}$ Service \\ d'Anatomo-cyto-pathologie, Hôpital \\ Ambroise Paré, APHP, Boulogne, \\ France
}

\begin{abstract}
In 1998, gastrointestinal stromal tumor (GIST) emerged as a distinct oncogenetic entity and subsequently became a paradigm of targeted therapies in solid tumors. Diagnosis of GIST relies on both histology and immunohistochemistry. Ninety-five percent of GISTs express either KIT or DOG-1. Approximately $80 \%-90 \%$ of GISTs harbor gain-of-function mutations of either KIT or platelet-derived growth factor receptor alpha polypeptide (PDGFRA) receptor tyrosine kinase (RTK). More than 100 different mutations have been described, some of which are associated with specific clinical and/or histological characteristics. Detection of KIT or PDGFRA mutations is recommended in advanced GISTs because they are highly predictive of tumor response to RTK inhibitors, as well as in KIT-negative cases to confirm diagnosis. In most cases, GISTs are sporadic, but in rare cases, they are related with genetic predisposition, such as neurofibromatosis type 1, Carney triad, Carney-Stratakis syndrome, and inherited KIT or PDGFRA germline mutations.
\end{abstract}

Keywords: gastrointestinal stromal tumors, KIT, PDGFRA, genetic predispositions, imatinib

\section{Introduction}

Until the late 1990s, gastrointestinal stromal tumors (GISTs) were often misdiagnosed as other gastrointestinal mesenchymal tumors, such as leiomyoma, leiomyosarcoma, or schwannoma. In 1998, Hirota et al $^{1}$ demonstrated the critical role of KIT receptor tyrosine kinase (RTK)-activating mutations in GISTs, and KIT immunostaining became a major diagnostic tool. Only 3 years later, the KIT inhibitor imatinib was shown to have dramatic antitumor effects, and this rare and frequently undiagnosed tumor became the paradigm of targeted therapies. This review updates knowledge on GIST and highlights the knowledge on genetic alterations.

\section{GIST pathogenesis}

GISTs are thought to be derived from intestinal cells of Cajal or precursors because of their digestive origin and the expression of KIT. ${ }^{2}$ Physiologically, the cells of Cajal have an autonomous pacemaker function and coordinate gastrointestinal peristalsis throughout the gastrointestinal tract. ${ }^{3}$ Gain-of-function mutations of proto-oncogenes $K I T$ or platelet-derived growth factor receptor alpha polypeptide ( $P D G F R A$ ) play a critical role in GIST pathogenesis. ${ }^{1,4}$ They are found in $85 \%$ of GISTs, in either KIT for $75 \%-80 \%$ or PDGFRA for $5 \%-10 \%$, and are mutually exclusive. ${ }^{5}$

Correspondence: Jean-François Emile Department of Pathology, Ambroise Paré University Hospital, 9 Ave Charles De Gaulle, Boulogne 92104, France

Tel +33 । 49095725

Fax +33 I 49095872

Email jean-francois.emile@apr.aphp.fr

\section{Epidemiology}

GISTs are the most frequent mesenchymal tumors of the digestive tract. The incidence peak and the median age at diagnosis is of about 60-65 years. However, the distribution 
by age is wide, and GIST can occur during childhood or at 90 years of age. ${ }^{6-8}$ Most epidemiological studies reported a slight male predominance. ${ }^{7-10}$ In western countries, the estimated annual incidence reported in population-based studies is between 11 and 15 per million people. ${ }^{9-11}$ This commonly accepted incidence was estimated from pathologic registry in all cases ${ }^{9-11}$ and is probably underestimated because GIST tumorlets (size of $1-10 \mathrm{~mm}$ ) are found frequently in autopsies. ${ }^{12}$ GISTs are sporadic in their great majority but, in rare cases, occur in patients with genetic predisposition. These rare cases are described in detail in this review.

\section{Location and symptoms at diagnosis}

Typically, the tumor occurs in the stomach for $66 \%$ or in the small intestine for $25 \%$ of most cases, but they might occur along the entire length of the digestive tract from the esophagus to the anus and sometimes in the omentum and the mesentery. ${ }^{6,13}$ Therefore, most GISTs arise from the bowel wall with a frequently slow and extra-luminal tumor development. Symptoms of the disease are nonspecific and reflect these features. ${ }^{7-9}$ GISTs can be revealed by gastrointestinal bleeding, solid mass at palpation, pain, abdominal discomfort, and early satiety, and acute abdomen emergency can sometimes occur. The diagnosis is also frequently made incidentally. ${ }^{7,8,14}$

In cases of advanced GISTs, most metastases arise in the liver and/or peritoneal cavity. Other metastases in lung, pleura, bones, or other areas are less frequent., ${ }^{7,8,14,15}$ Lymph node metastases are unusual, and lymphadenectomy is warranted only for evident nodal involvement or for rare pediatric GISTs. ${ }^{16}$

\section{Risk assessment after curative surgery}

Until last year, GISTs were often described as benign or of uncertain malignant potential. Subsequently, after the discovery and well characterization of the KIT role, it was suggested that all GISTs have malignant potential, and many prognostic factors have been assessed to estimate the risk of relapse after curative surgery. ${ }^{6,17-22}$ Nevertheless, to be used in routine practice, prognosis factors have to be robust, reproducible, and easy to assess. These considerations led to the adoption of a consensus risk classification based on the combination of the maximal tumor size and the mitotic count per 50 high-power fields (hpf) in 2002 (Table 1A). ${ }^{16,23}$ However, the relative good prognosis of patients with gastric GIST of all size with low mitotic activity called into question the concept of the generally malignant nature of GIST. ${ }^{7}$ Moreover, it was demonstrated that gastric GISTs have a
Table I A Classifications for risk assessment after curative surgery. Consensus approach published by Fletcher et al in $2002^{23}$

\begin{tabular}{lll}
\hline Risk group & $\begin{array}{l}\text { Maximal } \\
\text { tumor diameter }\end{array}$ & $\begin{array}{l}\text { Mitotic } \\
\text { count/50 hpf }\end{array}$ \\
\hline Very low risk & $<2 \mathrm{~cm}$ & $<5$ \\
Low risk & $2-5 \mathrm{~cm}$ & $<5$ \\
Intermediate risk & $<5 \mathrm{~cm}$ & $6-10$ \\
& $5-10 \mathrm{~cm}$ & $<5$ \\
High risk & $5-10 \mathrm{~cm}$ & $6-10$ \\
& $>10 \mathrm{~cm}$ & any \\
& any & $>10$ \\
\hline
\end{tabular}

better prognostic outlook than intestinal GISTs of similar size and mitotic index. ${ }^{24}$ Thus, Miettinen and Lasota ${ }^{24}$ proposed a new classification including the anatomic site as a third independent prognostic factor and defined a new subclass of benign GIST (Table 1B). More recently, a prognostic normogram using the same three factors was developed and validated in three independent large cohorts. ${ }^{25}$

\section{Treatment in advanced GIST}

GISTs are highly resistant to conventional chemotherapy and radiotherapy, and during many years, the only curative treatment was surgery even in cases of advanced disease. Understanding the molecular physiology of GIST has allowed development of targeted therapies. Today, two small molecule tyrosine kinase inhibitors with activity against KIT and PDGFRA, among others, are approved in patients with GIST: imatinib (Glivec ${ }^{\circledR}$, Gleevec ${ }^{\circledR}$; Novartis, Basel, Switzerland) and sunitinib (Sutent ${ }^{\circledR}$; Pfizer, New York, NY).

In patients with advanced GIST, imatinib efficacy was initially described in a single patient. ${ }^{26}$ After rapid development, it is today the first-line reference treatment in advanced GISTs, achieves disease control in $70 \%-85 \%$ of patients with a median progression-free survival (PFS) of 20-24 months and a median overall survival (OS) of 50-55 months. ${ }^{27,28}$ Nevertheless, imatinib is not curative, and its interruption results in rapid progression in most patients. ${ }^{29}$ Under imatinib, secondary resistance occurred in $15 \%-20 \%$ of patients each year.

Recently, retrospective studies suggested a potential benefit of secondary metastases resection in patients with a good response under imatinib. ${ }^{30-32}$ Prospective randomized trials should soon evaluate such strategy and allow recommendations to be made. In the opposite, patients with disease progression did not seem to benefit from surgery and should be considered for other targeted therapies. ${ }^{30-32}$ Among them, sunitinib has proved its efficacy with a median PFS of 6-8 months, and it is approved in second-line treatment. ${ }^{33,34}$ 
Table IB Classification with GIST location proposed by Miettinen and Lasota in $2006^{24}$

\begin{tabular}{|c|c|c|c|c|c|c|}
\hline \multirow[t]{2}{*}{ Risk roup } & \multirow{2}{*}{$\begin{array}{l}\text { Maximal tumor } \\
\text { diameter }\end{array}$} & \multirow{2}{*}{$\begin{array}{l}\text { Mitotic } \\
\text { count/50 hpf }\end{array}$} & \multicolumn{4}{|c|}{ Estimated rate of relapse according to GIST location } \\
\hline & & & Gastric & Jejuno ileal & Duodenal & Rectal \\
\hline I & $\leq 2 \mathrm{~cm}$ & $\leq 5$ & 0 & 0 & 0 & 0 \\
\hline 2 & $>2-\leq 5 \mathrm{~cm}$ & $\leq 5$ & $1.9 \%$ & $4.3 \%$ & $8.3 \%$ & $8.5 \%$ \\
\hline $3 a$ & $>5-\leq 10 \mathrm{~cm}$ & $\leq 5$ & $3.6 \%$ & $24 \%$ & $-^{\mathrm{b}}$ & $-{ }^{\mathrm{b}}$ \\
\hline $3 b$ & $>10 \mathrm{~cm}$ & $\leq 5$ & $12 \%$ & $52 \%$ & $34 \%$ & $57 \%$ \\
\hline 4 & $\leq 2 \mathrm{~cm}$ & $>5$ & 0 & $50 \%$ & - & $54 \%$ \\
\hline 5 & $>2-\leq 5 \mathrm{~cm}$ & $>5$ & $16 \%$ & $73 \%$ & $50 \%$ & $52 \%$ \\
\hline $6 a$ & $>5-\leq 10 \mathrm{~cm}$ & $>5$ & $55 \%$ & $85 \%$ & $-^{\mathrm{b}}$ & $-^{\mathrm{b}}$ \\
\hline
\end{tabular}

Notes: a The mitotic count was made in a $5 \mathrm{~mm}^{2}$ surface, which corresponds to $20-25$ fields at $\times 400$ magnification with recent microscopes; bSubgroups with insufficient number of patients to estimate the rate of relapse risk.

Abbreviations: GIST, gastrointestinal stromal tumors; hpf, high-power fields.

In third-line treatment, promising results have been reported with sorafenib (Nexavar ${ }^{\circledR}$; Bayer, Leverkusen, Germany), ${ }^{35}$ and many other targeted therapies like nilotinib (Tasigna ${ }^{\circledR}$; Novartis) or dasatinib (Sprycel ${ }^{\circledR}$; Bristol-Myers Squibb, New York, NY) are in development at present. ${ }^{36,37}$

\section{Adjuvant treatment}

In cases of localized GIST, surgery remains the only curative treatment. After such resection, results of a randomized Phase III trial demonstrated that imatinib taken daily for 1 year significantly improved recurrence-free survival compared with placebo, and at 1-year follow-up, the hazard ratio was 0.35 (95\% CI: $0.22-0.53 ; P<0.0001) .{ }^{38}$ Two studies in progress are investigating treatment duration: the EORTC trial 62024 (no adjuvant treatment vs 2 years of imatinib) and the SSG trial XVIII (1 year vs 3 years of imatinib). In waiting results of those studies, 1 -year imatinib is today the standard treatment in adjuvant setting, and its indication has been approved recently in Europe in patients who are at significant risk of relapse.

\section{Diagnostic criteria}

Most GISTs are suspected with endoscopy or computed tomography (CT) scan or during surgery. However, definitive diagnosis relies on pathology, which is based on both histology and immunohistochemistry. As a result of advances in understanding GISTs pathogenesis and the rapid development of effective targeted therapies, international consensus criteria have been published for the diagnostic of GIST. ${ }^{16,23,39}$

\section{Endoscopy and imagery}

GIST can be found incidentally or after digestive symptoms during gastroscopy, colonoscopy, capsule endoscopy, or enteroscopy. ${ }^{40,41}$ GIST is a submucosal tumor and is observed at endoscopy as a bulge underneath the mucosa of the gastrointestinal tract. The digestive mucosa is of normal appearance, but a mucosal ulceration secondary to tumor growth is common and can induce gastrointestinal bleeding. Superficial mucosal biopsies are generally noncontributive. Endoscopic ultrasound is the most important tool to assess its layer of origin, particularly in cases of small GIST. ${ }^{39}$ It allows it to equally perform guided fine-needle aspiration or trucut biopsy. These two techniques are safe and comparable but have only limited value for GIST diagnostic because of a high rate of technical failure. ${ }^{40,41}$ In cases of localized GIST, the best tissue acquisition technique remains surgical resection, and multiple core needle biopsies are recommended only in large tumor cases, which involve multivisceral resection. ${ }^{39}$ When submucosal tumor is less than $2 \mathrm{~cm}$ in size, and so probably a GIST of low risk, one standard approach is to follow it with endoscopic ultrasound, reserving resection for growing tumors. For tumors larger than $2 \mathrm{~cm}$ or rectal tumors of worse prognosis, biopsy/excision should be made for definitive diagnostic. ${ }^{39}$

The diagnostic of GIST is often suggested on CT scan. Typically, tumors are described as a large well-circumscribed tumor arising from the stomach or small bowel. They are predominantly extra-luminal with lower signal intensity than that of the contrast material-enhanced liver. ${ }^{14}$ In most cases, large tumors have a heterogeneously enhancing soft-tissue rim surrounding a necrotic center, and small tumors are more homogeneous. Central gas, calcification, or fluid-fluid level suggest intratumoral hemorrhage is possible. For preoperative staging, CT scans and 18F-fluoro-deoxyglucose positron emission tomography (PET) are both useful. ${ }^{14,42,43}$ Although less precise for anatomic detail than CT scans, PET can reveal small metastases and is useful in cases of locally advanced GIST when early assessment of therapy effectiveness is of special concern. ${ }^{39,42-45}$ Like for rectal adenocarcinoma, 
magnetic resonance imaging provides better preoperative detail of perineal region and is recommended in cases of rectal GIST. ${ }^{39}$

\section{Standard histologic examination}

Histologically, GISTs can be most often classified in three categories: the spindle cell type that represents $70 \%$ of cases and is composed of relatively uniform eosinophilic cells arranged in short fascicles or whorls (Figure 1A), the epithelioid type that represents $20 \%$ of cases and is composed of rounded cells with eosinophilic or clear cytoplasm (Figure 1B), and the mixed type that contains the both cell types together. In uncommon cases, GISTs show a prominent myxoid stroma, a paraganglioma-like pattern, or a cytoplasmic pleomorphism. ${ }^{23}$ Necrosis and/or hemorrhage area are frequent in large GISTs, and the necrosis percent had been suggested as a prognostic factor in some studies. ${ }^{6}$ Tumor rupture, whatever the cause, should be recorded because of its adverse prognostic value. ${ }^{39}$

In resected GISTs, standard histologic description must be completed by the mitotic count, which was evaluated in $50 \mathrm{hpf}$ in the 2002 consensus risk classification. ${ }^{23}$ However, in the last classification proposed by Miettinen and Lasota, ${ }^{24}$ the mitotic count was made in a $5 \mathrm{~mm}^{2}$ surface, which corresponds to $20-25$ fields at $400 \times$ magnification by using a modern wide-field microscope with wide-field eye-pieces. Evaluation of adjuvant imatinib indication is of major importance for routine practice.

\section{Immunohistochemistry}

Ninety-five percent of GISTs show KIT immunostaining (CD117), but some variability in pattern exists. Most GISTs show unequivocal diffuse and strong cytoplasmic positivity. A cytoplasmic dot-like (Golgi pattern) staining is present in almost half of the cases and may be exclusive or associated with cytoplasmic pattern (Figure 1C). ${ }^{23}$ Interestingly, Golgi staining is correlated with KIT mutation and is significantly more frequent in GISTs with homozygous mutations. ${ }^{46}$ These results are consistent with experimental data in which KIT mutant proteins remain within endoplasmic reticulum or Golgi compartments and do not reach the cell membrane. ${ }^{47}$ Stromal mast cells are a valuable internal positive control for KIT immunostaining. Although highly specific, KIT immunostaining can be positive in other tumors, in particular in small-cell lung cancer, testicular teratocarcinoma, melanoma, and angiosarcoma. ${ }^{48-50}$ In these tumors, KIT mutations are uncommon with the exception of melanoma, ${ }^{49}$ and overexpression is mostly associated with genomic amplification of wild-type gene. ${ }^{48,50}$

Other immunohistochemical analyses are frequently used in GISTs diagnostic: 70\% of GISTs show immunopositivity for CD34, 40\% for smooth muscle actin (SMA), 5\% for S-100 protein, and 2\% for desmin..$^{16,23}$ CD34 and SMA immunopositivity seem to vary according to GIST location. ${ }^{51}$ Expression of PKC- $\theta$ was also used for GIST identification. ${ }^{4}$ However, the low specificity of these markers limits their relevance in routine practice of GISTs. By contrast, DOG-1 is useful for diagnosis of GISTs. DOG-1 was characterized using gene microarrays, and its protein function is unknown. It is expressed almost ubiquitously in GISTs irrespective of the type of activating mutations, is rarely expressed in other soft tissue tumors, and is positive in KIT-immunonegative GISTs with PDGFRA mutation (Figure 1D). ${ }^{52}$

\section{Activating mutations}

The screening of KIT and PDFGRA mutations may be performed on either formalin-fixed, paraffin-embedded, or frozen samples. Bouin fixation should be avoided since it may impair the molecular analysis feasibility. ${ }^{16} \mathrm{~A}$ histological examination to spot tumor areas must be performed before all DNA extraction. Because of the relative tumoral homogeneity of GISTs, tumor tissue microdissection is not required in most cases. There is no recommendation for optimal mutation screening technique. Direct sequencing was performed in most previous studies. Length analysis of polymerase chain reaction (PCR) products is more sensitive than direct sequencing for detection of deletions and insertions (Figure 2A). ${ }^{4}$ Moreover, this technique allows for rapid screening for the most frequently mutated exons and to guide direct sequencing. In absence of length modification, direct sequencing of all putative mutated exons must be done to search point mutations (Figures 2B-2D). Denaturing highperformance liquid chromatography is another very sensitive technique, which allows detection of deletions, insertions, and substitutions. ${ }^{53}$ The frequencies of KIT and PDGFRA mutations in advanced GISTs are detailed in Table $2 .{ }^{5}$ The search of mutations must be done in specialized laboratories implicated in a quality assurance program. ${ }^{39}$

\section{Diagnostic recommendations}

In most cases, the diagnosis of GIST relies on concordant histology and KIT immunopositivity. A central review by an expert in sarcoma pathology should be made for equivocal cases. In the rare cases of KIT-negative tumors (5\%), molecular analysis for KIT and PDGFRA has a diagnostic 

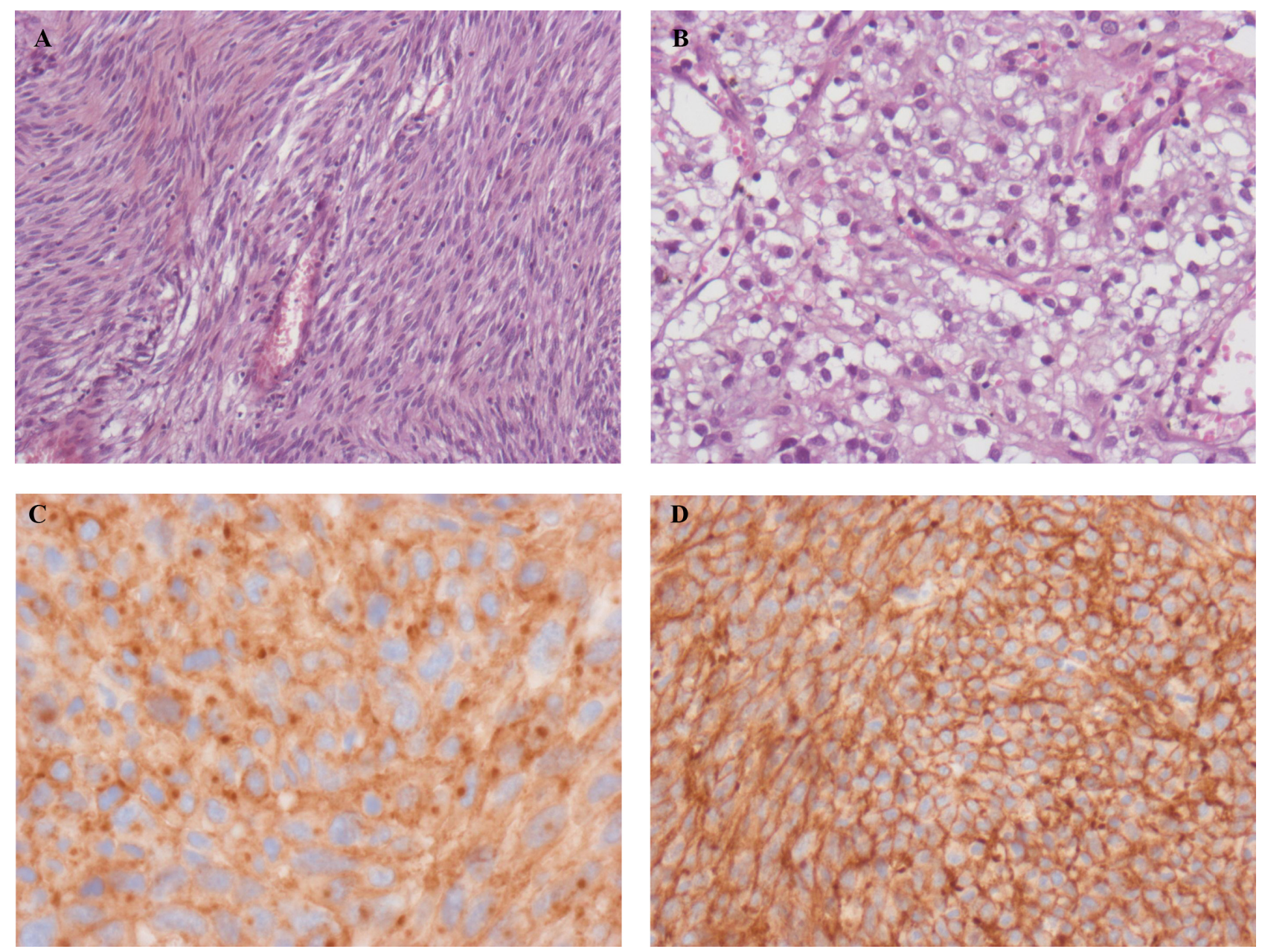

Figure I Histologic features of gastrointestinal stromal tumors (GISTs). A) Spindle cell type. B) Epithelioid cell type. C) CDII7 (KIT) immunostaining with cytoplasmic dot-like (Golgi) pattern and cytoplasmic pattern. D) GIST positive with DOG-I immunostaining.

interest, and other markers such as DOG-1 have to be considered. ${ }^{16,23,39}$

Mutational analysis for activating mutations is strongly recommended in all advanced GISTs because of their predictive value ${ }^{39}$ This specific point will be discussed in detail in the next section.

\section{Type of mutations and specificities KIT and PDGFRA mutations}

More than $80 \%$ of GISTs contain activating mutations of KIT or PDGFRA. ${ }^{5}$ Both receptors are members of the type III receptor protein-tyrosine kinase family and encode a transmembrane RTK. Binding of ligand (stem cell factor [SCF] for KIT) results in dimerization of the receptor, activation of its kinase activity, and phosphorylation of several proteins implicated in signaling pathways known to promote cell growth and survival. ${ }^{54}$ Both receptors activate the downstream phosphatidylinositol-3-kinase (PI3K)-AKT, mitogen-activated protein (MAP)-kinase, and Janus kinase-signal transducer and activator of transcription (JAK-STAT3) signaling cascades. ${ }^{54,55}$ Activating mutations consist of in-frame deletions, insertions, or missense mutations, and result in constitutive receptor activation independent of ligand binding. Mutations can occur in the extracellular domain (KIT exon 9), in the juxtamembrane domain (KIT exon 11 and PDGFRA exon 12), in the kinase I domain (KIT exon 13 and PDGFRA exon 14), and in the kinase II domain (KIT exon 17 and PDGFRA exon 18$){ }^{5}$

KIT mutations are found in $75 \%-80 \%$ of GISTs, and $60 \%$ of them are within the exon 11 of $K I T,{ }^{5,6,55}$ which comprises 33 codons (codons 550-582). KIT exon 11 encodes an intracytoplasmic juxtamembrane domain, which has an autoinhibitory function. ${ }^{56}$ Normally, after dimerization, transphosphorylation of two tyrosine residues (Tyr568 and 
A

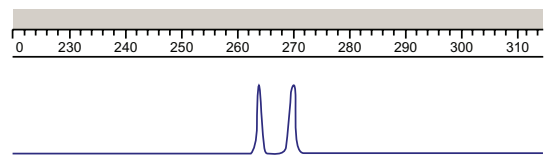

B

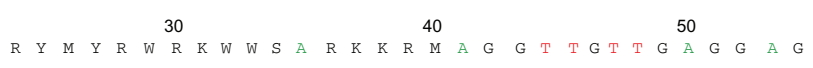

C

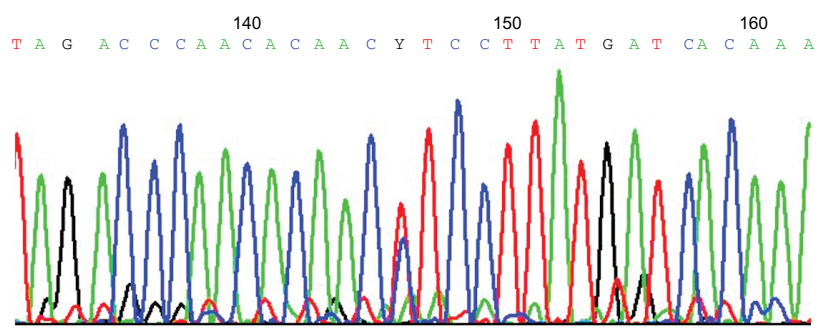

D

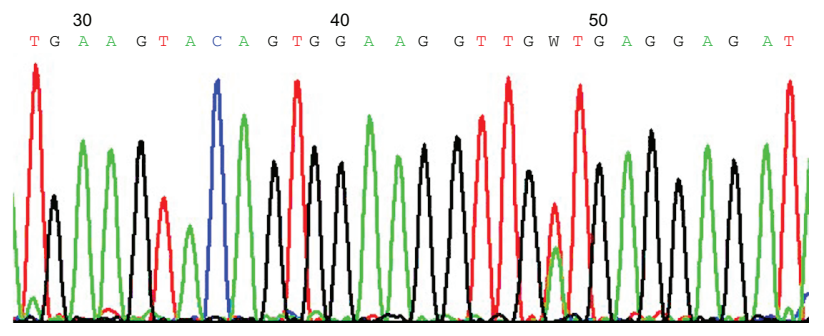

Figure 2 Diagnostic of KIT-activating mutations. A) Deletion of KIT exon II detects with length analysis of polymerase chain reaction products. The normal allele is on the right, and the mutated allele with two codons deleted is on the left. B) Sequencing of KIT exon II with delWK557-558 heterozygous deletion. C) Sequencing of KIT exon II with L576P point mutations. D) Sequencing of KIT exon II with V560D point mutations.

Tyr570) in the juxtamembrane segment occurs, and the loop formed by exon 11 is converted from a compact inactive conformation to an extended active conformation..$^{57,58}$ Mutations occurring in exon 11 disrupt this normal autoinhibitory function and promote spontaneous kinase activation. ${ }^{57,59}$ More than 90 mutations of exon 11 have been published: ${ }^{60-69} 85 \%$ are in-frame deletions or insertions and $15 \%$ are missense mutations. The most frequent mutation is a short deletion in the proximal part of exon 11, delWK557-558, accounting for $8 \%-25 \%$ of KIT exon 11 mutations. ${ }^{60-69}$ Other KIT mutations are located within exon 9 in $10 \%$ of cases, consisting in most cases of in-frame insertions or within exons 13 or 17 in
$1 \%$ for each. ${ }^{55}$ PDGFRA mutations are found in $5 \%-7 \%$ of GISTs. They are located within exon 18 in 5\% of GISTs and within exon 12 or 14 in $1 \%$ of GISTs. ${ }^{5}$ The most frequent exon 18 mutation is a substitution, $\mathrm{D} 842 \mathrm{~V}$, and accounts for $30 \%-80 \%$ of PDGFRA mutations. ${ }^{55,63,65,66,70}$ KIT or PDGFRA mutations are heterozygous in $95 \%$ of mutated GISTs. ${ }^{6}$ In rare cases, homozygous mutations could result from a loss of $K I T$ wild-type allele and duplication of the mutant. ${ }^{71}$

\section{KIT transcriptional regulation}

To better understand the critical role of KIT in GIST pathogenesis, many studies have focused on KIT regulation. KIT

Table 2 Activating KIT or PDFGRA mutations and therapeutic implications

\begin{tabular}{|c|c|c|c|c|}
\hline $\begin{array}{l}\text { Activating } \\
\text { mutations }\end{array}$ & $\begin{array}{l}\text { Frequency at } \\
\text { diagnosis }\end{array}$ & $\begin{array}{l}\text { Predictive value } \\
\text { for imatinib }^{\mathbf{a}}\end{array}$ & $\begin{array}{l}\text { Secondary mutations } \\
\text { of imatinib resistance }{ }^{90,93-97}\end{array}$ & $\begin{array}{l}\text { Predictive value } \\
\text { for sunitinib }^{\mathbf{b}}\end{array}$ \\
\hline \multicolumn{5}{|l|}{ KIT } \\
\hline Exon 9 & $10 \%$ & $70 \%-75 \%$ & & $58 \%$ \\
\hline Exon II & $67 \%$ & $90 \%-95 \%$ & & $34 \%$ \\
\hline Exon 13 & $1 \%$ & \pm & Yes & + \\
\hline Exon 14 & $0 \%$ & & Yes & + \\
\hline Exon 17 & $1 \%$ & \pm & Yes & - \\
\hline Exon 18 & $0 \%$ & & Yes & - \\
\hline PDGFRA & & $33 \%-60 \%$ & & \\
\hline Exon 12 & $1 \%$ & + & & \\
\hline Exon 14 & $<1 \%$ & + & & \\
\hline Exon 18 & $5 \%$ & \pm excepted for $D 842 V$ & Yes & - for D842V \\
\hline Wild type & $12 \%-15 \%$ & $33 \%-73 \%$ & & $56 \%$ \\
\hline
\end{tabular}

Notes: aPercent of disease control rate; + : in vitro sensitivity, described as response, and not reported as secondary mutations; \pm : described response cases, in vitro sensitivity, but also as secondary mutations; ${ }^{66,86}$ b According to primary or secondary mutations; percent of disease control rate; +: sensitive; -: resistant. ${ }^{96,102}$ 
contains 21 exons, and two alternative splicing sites have been described. One is located at the $3^{\prime}$ end of exon 9 and results in the transcription of two isoforms, GNNK- and GNNK.$+{ }^{72}$ Although the GNNK - isoform was the predominant isoform and has been reported to have a greater oncogenic potential than the GNNK,$+{ }^{73}$ the GNNK-/+ ratio was similar in GISTs than in normal interstitial cells of Cajal and control mast cells. ${ }^{74}$ In heterozygous mutated GISTs, similar amounts of both allele and both transcripts were found, and so, the oncogenic effects of KIT in GISTs do not seem related to a variation in transcripts ratio.

Interestingly, KIT messenger RNA (mRNA) amounts were higher in heterozygous mutated GISTs than in homozygous mutated and nonmutated GISTs. ${ }^{74,75}$ Using quantitative PCR and fluorescence in-situ hybridization (FISH), it was demonstrated that KIT amplification was not implicated in KIT overexpression in the majority of GISTs. More, despite variable expressions between tumors, analysis of both quantified mRNA with real-time PCR (RT-PCR) and protein levels with Western blot show a close correlation between these two regulation levels. ${ }^{75} \mathrm{~A}$ fraction of KIT was phosphorylated and activated in all GISTs, but this amount was not correlated with the mutational GISTs status. ${ }^{76}$ These data suggested a transcriptional regulation of KIT overexpression in GISTs.

Subsequent analysis of SCF production by RT-PCR, immunohistochemistry, and enzyme-linked immunosorbent assay demonstrated that KIT ligand and both its transcript isoforms were present in almost all tested GISTs and in three primary cultures. ${ }^{76}$ Indeed, SCF is produced by different cell types, and SCF mRNA and protein were detected in almost all normal digestive control samples. Previous in vitro data have reported that SCF treatment of GIST cells with heterozygous KIT mutation induced a stronger KIT tyrosine phosphorylation, ${ }^{77}$ while it did not in GIST cells with homozygous KIT mutation. ${ }^{78}$ Thus, SCF may activate wild-type KIT in nonmutated GISTs and modulate the fraction of activated KIT in heterozygous
GISTs. These results suggest that an autocrine/paracrine mechanism may play a role in GISTs pathogenesis. ${ }^{76}$

\section{KIT translational regulation}

Two forms of KIT protein are described in GISTs. ${ }^{79}$ The $125 \mathrm{kDa}$ form is the precursor of the $145 \mathrm{kDa}$ form and lacks the complex glycosylation necessary for its cell surface targeting. ${ }^{80}$ In vitro data suggested that intracellular signaling activated by the $125-\mathrm{kDa}$ mutant form was sufficient to drive neoplasia KIT. ${ }^{80}$ KIT immunohistochemistry staining show that paranuclear dot-like patterns were significantly more frequent in homozygous mutated GISTs than in heterozygous or nonmutated GISTs. ${ }^{47,81}$ These results are supported by Western blot analyses. While the phosphorylated mature form of KIT is found in almost all GISTs irrespective of mutational status, the phosphorylated immature form is detected in GISTs with KIT mutation but not or weakly in nonmutated GISTs. ${ }^{47,77}$ In NIH3T3 cells infected with wildtype or mutated exon 11 KIT complementary DNA, KIT was predominantly found in the perinuclear region in mutated cells, whereas it was diffusely present in the cytoplasm and at the plasma membrane in wild-type cells. Mutant KIT was mainly retained in an phosphorylated immature form within Golgi and endoplasmic reticulum compartments, whereas wild-type KIT was expressed in a nonphosphorylated form at the plasma membrane. Moreover, stimulation with SCF and inhibition with imatinib have different effects according to mutational KIT status. In wild-type cells, SCF treatment significantly decreased the cell surface expression of KIT and imatinib restored it. In mutated cells, SCF treatment had no effect on KIT membrane expression, whereas imatinib blocked mutant KIT phosphorylation, restored normal maturation, and increased membrane expression. ${ }^{47}$ Activating KIT mutations induce an alteration of normal maturation and intracellular trafficking of receptor, and are associated with an

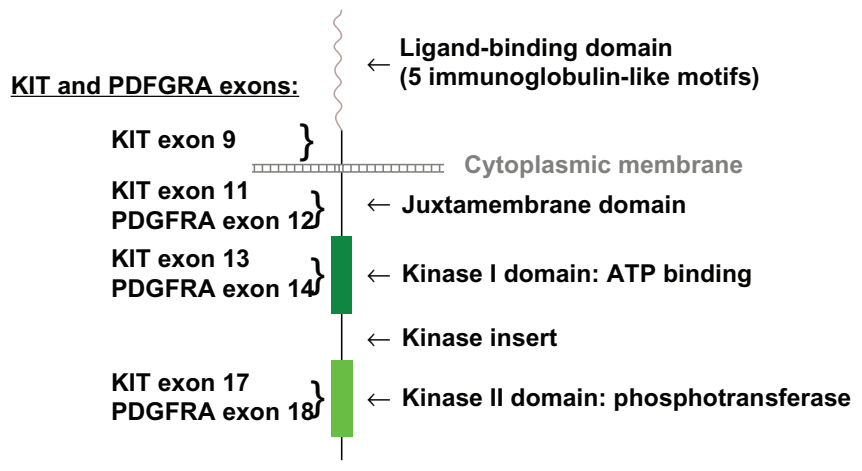

Figure 3 Schematic representation of KIT and PDGFRA receptor tyrosine-kinase.

Abbreviations: ATP, adenosine triphosphate; PDGFRA, platelet-derived growth factor receptor alpha polypeptide. 
intracellular activation of its immature form. These results are important because they suggest that only targeted therapies able to enter cells may be effective against mutated KIT. They also constitute a possible explanation of the absence of correlations between KIT immunohistochemistry staining and imatinib efficacy. ${ }^{82}$ We currently do not know if wild-type and mutant KIT might activate different signaling pathways according to their intracellular location and interactions with other proteins or if both allele have exactly the same activation pathways.

\section{Location and prognosis}

Many studies described that GISTs location was associated with type of mutation. GISTs with KIT exon 9 mutation arise predominantly in small intestine and colon, and those with PDGFRA mutations most often originate from the stomach. ${ }^{6,63,65,83}$ Recently, we reported that GISTs with a deletion of the two tyrosine residues of exon 11 (delTyr) arise in the small intestine, colon, or rectum in about $70 \%$ of cases, whereas those with delWK557-558 occur in the stomach in about $75 \%$ of cases, and that this difference was highly significant. ${ }^{84}$ These data suggest possible different types of oncogenic events driving KIT mutations in the different parts of the digestive tract.

GIST prognostic also seems to be associated with type of mutation. Tumors with PDGFRA mutations are most often benign than those with KIT mutations, ${ }^{83}$ and those with KIT exon 9 or 11 mutations have been described to be associated with malignant behavior. ${ }^{55}$ The type of mutations in a same exon may equally be prognostic. Exon 11 deletions and deletions affecting codons 557-558 of KIT exon 11 were described to be independent adverse prognostic factors in patients with GIST. ${ }^{64,68,85}$ Conversely, in another study, GISTs in which the last part of exon 11 (codons 562-579) were deleted were most frequently associated with malignancy than GISTs with deletion of the first part of exon 11 (codons 550-561).6,69 Subsequently, we reported that GISTs with delWK557-558 and GISTs with delTyr did not differ in the risk of relapse after curative surgery and both convey a poor prognosis. ${ }^{84}$ Thus, the prognostic value of the type of KIT exon 11 mutations remains unclear, and more data are required. Recently, it was suggested that the homozygous/ heterozygous status of mutant exon 11 KIT may be equally prognosis. In two small series, GISTs with homozygous exon 11 mutations were associated with a malignant behavior in about $90 \%$ of cases. ${ }^{71,81}$ This worsened prognosis could be explained by at least two hypotheses: on the one hand, homozygous status with the loss of the wild-type allele may have a highly intrinsic oncogenic effect (by loss of regulatory mechanisms), and on the other hand, homozygous status may be only a marker of late-stage tumors that have undergone multiple genetic events. ${ }^{71,81}$ Because these studies are all retrospective and have included relatively few patients, their results have to be taken with caution and require confirmation. In future, analysis of international adjuvant trials according to mutations type will probably permit progress in the understanding of their prognostic value.

\section{Predictive value}

The mutational status of KIT or PDGFRA is highly predictive of clinical response to imatinib. In randomized trials, disease control rates (partial response and stable disease) assessed by Response Evaluation Criteria In Solid Tumours (RECIST) criteria were 90\%-95\% in KIT exon 11 mutations, $70 \%-75 \%$ in KIT exon 9, 33\%-60\% in PDGFRA, and $33 \%-73 \%$ in wild-type GISTs. ${ }^{66,86}$ Patients with exon 11 mutations have a significant longer PFS and OS than patients with exon 9 mutations or wild-type GIST, and there was no difference between patients with exon 9 mutations and those with wild-type GIST. ${ }^{66,86}$ Imatinib is a competitive inhibitor of adenosine triphosphate (ATP) and can only bind to the inactive conformation of KIT. In inactive conformation of KIT, imatinib is too large to bind to an ATP-binding pocket and is blocked by an $\alpha$-helical conformation of KIT of exon 11. Modification in juxtamembrane conformation caused by exon 11 mutations allows an imatinib binding and an inhibition of KIT activity, giving a structural explanation for the predictive value of exon 11 mutations. ${ }^{56}$ Some authors have proposed that deletion of codon 565 could be a predictive factor among patients harboring exon 11 mutations. ${ }^{66}$ Nevertheless, the outcome of nonresectable and metastatic GISTs with delWK557-558 and delTyr under imatinib was similar in terms of response rates, PFS, and OS in one of our study. Moreover, all patients included had an objective response or a stable disease under imatinib, and median PFS were of about 20 months. ${ }^{84}$ Thus, the predictive value of the type of exon 11 mutations remains still to be determined.

In the meta-analysis of the two Phase III trials that compared $400 \mathrm{mg}$ daily and $800 \mathrm{mg}$ daily of imatinib, objective response rates and OS were not significantly different between the two arms. ${ }^{87}$ However, there was a small significant PFS advantage for the 800-mg arm. In multivariate analysis, exon 9 mutations was the only significant factor for the benefit of $800 \mathrm{mg}$ daily dose $(P=0.012) .{ }^{87}$ This high dose is today the standard recommended dose in patients with exon 9 mutation, whereas the $400 \mathrm{mg}$ dose is recommended 
in all other cases. ${ }^{39}$ For KIT mutations within exons 13 and 17 , no definitive conclusion can be made because of their low frequency. Interestingly, when these mutations were located within kinase domains, disease control was obtained in the majority of patients treated with imatinib in prospective trials. ${ }^{66,86}$ Concerning PDGFRA mutations, concordant in vitro data and clinical results support that the D842V substitution and other mutations within the kinase domain activation loop (exon 18) are predictive of primary resistance to imatinib, whereas it is efficient in cases of juxtamembrane domain mutations. ${ }^{66,86,88}$

In short, almost all GIST with exon 11 mutations responded to imatinib, patients with exon 9 mutations should receive a $800 \mathrm{mg}$ daily dose of imatinib, and D842V PDG$F R A$ mutation is predictive of primary resistance.

\section{Secondary resistance and sunitinib in second line}

Imatinib is not curative, and secondary resistance occurred in $15 \%-20 \%$ of patients each year. Many different mechanisms of secondary resistance have been described: genomic amplification and overexpression of KIT or PDFGRA; ${ }^{89,90}$ switch to another kinase activation with overexpression of the AXL RTK that stimulates oncogenic cell cycling; ${ }^{91}$ and levels of $\mathrm{ABCB} 1$ and $\mathrm{ABCC} 1$ proteins that are implicated in multidrug resistance and in ATP-dependent elimination of imatinib. ${ }^{92}$ However, the most frequent mechanism consists in the acquisition of a more novel mutation within KIT or PDGFRA..$^{90,93-97}$ In all described cases, more novel mutation occurred in the same RTK than the primary mutation (either KIT or PDGFRA), and no secondary mutations have been identified in wild-type GISTs. ${ }^{96}$ Moreover, in the same patient, different secondary mutations can occur in different metastases and/or in the same metastases. ${ }^{98}$ These secondary mutations involved either the ATP-binding pocket of the kinase I domain (KIT exons 13 and 14) or the kinase II domain activation loop (KIT exons 17 and 18). ${ }^{90,93-97}$ Similarly to the predictive value of exon 11 mutation, structural and functional understanding of KIT-imatinib interaction can explain occurrence sites of secondary mutations. Imatinib binding can be directly inhibited by mutations involving the ATP-binding pocket, ${ }^{99,100}$ and mutations involving the activation loop could strongly increase the proportion of KIT in active conformation, decreasing the possibility of KIT to bind to inactive forms. ${ }^{96}$ Interestingly, clonal evolution consecutive to novel mutation acquisition can be found as an enhancing nodule within a previously responding low-signal lesion on contrast-enhanced CT scans many months before progression defined by RECIST criteria. ${ }^{97,101}$
As for imatinib in first line, response to second-line sunitinib is correlated with the type of primary mutation. ${ }^{102}$ Nevertheless, at the opposite, disease control rate (for at least 6 months) were higher in exon 9 mutations (58\%) and wild-type GISTs (56\%) than in exon 11 mutations (34\%). PFS and OS were also significantly longer for patients with exon 9 mutations and patients with wild-type GIST than for those with exon 11 mutations. ${ }^{102}$ After progression under imatinib, sunitinib efficacy is also influenced by the type of secondary mutation. Among patients with a secondary KIT mutation identified, PFS was significantly longer for the 18 patients with KIT exons 13 or 14 mutations than for the 13 patients with KIT exons 17 or 18 mutations (7.8 months vs 2.3 months; $P=0.016$ ). Disease control rate and OS were equally better in patients subgroup with exons 13 or 14 mutations. ${ }^{102}$ Moreover, these results were supported by in vitro data. Sunitinib was efficient against secondary ATP-binding pocket mutations but has inferior potency than imatinib against some activation loop mutations. Moreover, the D842V PDGFRA mutation, classically resistant to imatinib, confers also a sunitinib resistance in vitro. ${ }^{102}$

\section{Genetic predisposition}

GIST can occur in patients with genetic predisposition in rare cases. Neurofibromatosis type 1 (NF-1) confers an increased risk of developing GISTs as many other tumors. ${ }^{103}$ GISTs are associated with two rare tumor syndromes, the Carney triad and the Carney-Stratakis syndrome, and germline mutations have been identified in rare families with multiple occurrences of GIST among relatives. Some clinical, pathological, and/or biological features are associated with each of these genetic predispositions.

\section{Neurofibromatosis type I}

Neurofibromatosis type $1(\mathrm{NF}-1)$ is one of the most frequent autosomal dominant disorders and affects 1/3000 individuals worldwide. ${ }^{104}$ The $N F 1$ gene encodes the neurofibromin, a large protein that acts as a negative regulator of the Ras protein. ${ }^{105}$ Inactivating mutation of $N F 1$ results in the hyperactivation of Ras and of downstream pathways such as MAP-kinase, which is implicated in antiapoptotic and growth signaling. ${ }^{106}$ Café-au-lait spots, axillary and inguinal freckling, neurofibroma, optic glioma, and iris Lisch nodules are among the primary clinical features of NF-1 and are used as major criteria for the clinical diagnosis. ${ }^{107}$ Other manifestations included skeletal, vascular, neurological, and psychiatric disorders. ${ }^{108}$ Other malignancies like astrocytomas 
and pheochromocytoma occur with increased frequency in patients with NF-1. ${ }^{103,108,109}$

The risk for GIST in patients with NF-1 is estimated to be as high as $7 \% .{ }^{103}$ Median age at diagnosis is 50 years, and almost $20 \%$ of patients are aged less than 40 years. Like sporadic GISTs, there is a slight male predominance (60\% of cases). Typically, tumors occur in the small intestines (duodenum, jejunum, or ileum) and are multiple in $60 \%$ of cases. Their size is variable, ranging from $10-0.1 \mathrm{~cm}$ in published series. ${ }^{110-112}$ The majority of them are small and have a low mitotic index. They are considered to have a good prognosis, but malignant behavior and subsequent diseaserelated death have been reported. ${ }^{112}$ Histologically, the great majority are of spindle cell phenotype, and almost all are positive for KIT immunohistochemistry. Nevertheless, KIT or PDGFRA mutation are usually absent in these GISTs. ${ }^{110-112}$ Thus, pathogenesis pathways involved in their development are different for sporadic GISTs, and some particular biological features have been described. NF-1-related GISTs are characterized by a low level of constitutive KIT autophosphorylation despite comparable KIT expression, a strong expression and activation of MAP-kinase pathways, a less strong activation of PI3K-AKT and JAK-STAT3 pathways than in sporadic GISTs, and the near absence of neurofibromin expression. ${ }^{113,114}$ Mitotic recombination or other genetic mechanisms resulting in the loss of wild-type allele and NF1 heterozygosity may be the key molecular event underlying GIST development in NF-1 patients. ${ }^{113,115}$ There are no clear data about their imatinib sensitivity, but in vitro data suggest that NF-1-related GISTs are not well controlled by imatinib, similarly to wild-type GISTs in general. ${ }^{113}$

\section{Carney triad and Carney-Stratakis syndrome}

Carney triad is a very rare tumor syndrome that was described in 1977. ${ }^{116}$ A heritable disorder was suspected because of multifocal tumors in multiple organs and the young age of patients. However, it was not a familial disorder. Typically, Carney triad-associated functioning includes extra-adrenal paraganglioma, pulmonary chondroma, and epithelioid gastric leiomyosarcoma, which were subsequently referred to as GIST. ${ }^{117}$ This disorder has a strong female predilection. In 1999, based on the analysis of 79 cases, adrenocortical adenoma and esophageal leiomyoma were added to the Carney syndrome, and the presence of two of the three initial components was defined sufficient for diagnostic as only $20 \%$ of cases had the third component. ${ }^{118}$ Analysis of features of gastric tumors in 104 patients with Carney syndrome show major differences from sporadic gastric GISTs. ${ }^{119}$ All patients had gastric tumors and at least one of the other Carney syndrome components. Median age at diagnosis was 18 years (ranged from 6 to 53 years), and about $90 \%$ of patients were female. Multiple gastric tumors were found in each patient; they were preferentially localized in the antrum (61\%) with a mean size of $6.3 \mathrm{~cm}$ (ranged from 0.2 to $18 \mathrm{~cm}$ ). Histologically, two-thirds were of epithelioid phenotype and all were KIT positive. Interestingly, there was no correlation of the assessed risk using the 2002 classification ${ }^{23}$ with subsequent malignant behavior. Lymph nodes were frequently involved. After a median follow-up of 21 years, 15 patients (14\%) died of gastric tumor evolution or therapeutic complication. Among the 16 patients treated by imatinib, the majority had no tumor response $(62 \%) .{ }^{119} \mathrm{KIT}$ or PDGFRA mutations are not found in gastric tumors of Carney syndrome, and the molecular events implicated in their pathogenesis are not known at present. ${ }^{120}$ Because of the clinical, pathological, and biological differences observed between gastric tumors of Carney syndrome and sporadic gastric GISTs, it was concluded that these tumors should not be labeled as GISTs but as gastric stromal tumors. ${ }^{119}$

In 2002, a new syndrome distinct from the Carney triad was described and named Carney-Stratakis syndrome. This syndrome was defined as an association of multiple paraganglioma and gastric GISTs occurring in an autosomal-dominant manner with incomplete penetrance. ${ }^{121}$ Gastric tumors of this syndrome have been described from five families. Clinical and pathological features of gastric tumors were very similar than those described for gastric stromal tumors of Carney triad. ${ }^{121}$ Subsequently, molecular abnormalities were investigated in 11 patients from nine unrelated families. Patients had gastric GIST and/or paraganglioma, and both tumor types were found in almost all families. ${ }^{122}$ No KIT or PDGFRA mutations were found, but eight patients from seven families had a germline mutation in one of the three succinate dehydrogenase subunit-encoding genes ( $S D H B, S D H C$, or $S D H D$ ). As in NF-1, allelic marker analysis suggested loss of wild-type allele of $S D H$ gene in gastric stromal tumors and paragangliomas. ${ }^{122}$ These genes are implicated in mitochondrial tumor suppressor pathways, and $S D H$ mutations have been described in sporadic or familial pheochromocytomas or extra-adrenal paragangliomas. ${ }^{123}$

\section{Particular cases of pediatric GISTs}

Pediatric GISTs are rare, and account for $1 \%-2 \%$ of all GISTs. ${ }^{124,125}$ Some of them can occur in a genetic predisposition matter (NF-1, Carney-Stratakis syndrome, KIT, or 
PDGFRA germline mutation), but most are sporadic. Pediatric GISTs are characterized by strong female predominance, gastric location in most cases, frequent multiple synchronous tumors and/or lymph node metastases, predominant epithelioid morphology, and the absence of KIT or PDGFRA mutations in most cases. Long survival may occur, even in the presence of metastases. ${ }^{124,125}$ Imatinib treatment may be less effective, and sunitinib, sorafenib, or third-generation tyrosine kinase inhibitors (dasatinib and nilotinib) have higher efficacy than imatinib in vitro. ${ }^{126}$ KIT downstream targets are activated in wild-type pediatric GISTs as in sporadic adult GISTs. ${ }^{126}$ However, gene expression analysis showed that wild-type pediatric GISTs (in Carney triad or not) had a distinct transcriptional signature than wild-type adult GISTs. ${ }^{125,126}$

Thus, pediatric GISTs (and most GISTs of adults under 30 years) are identical to Carney triad GISTs, clinically, morphologically, and genetically, and may represent a forme fruste of this syndrome or, alternatively, an independent subclass of GISTs with a same molecular pathogenesis. Data from paragangliomas and pheochromocytomas suggested that negative staining for SDHB was a marker of mitochondrial complex
II dysfunction, and this was regardless of which protein was disrupted. ${ }^{127,128}$ Thus, subsequently of the discovery of the role of $S D H$ mutations in Carney-Stratakis syndrome, some authors evaluated SDHB immunostaining in GISTs. Further supporting the hypothesis of a same pathogenesis, GISTs of Carney triad and pediatric wild-type GIST were negative for SDHB staining even without SDH mutations, while all GISTs with KIT mutations and NF-1-related GISTs were positive. ${ }^{129,130}$ Moreover, in sporadic adult GISTs, about $3 \%$ of tumors were negative for SDHB staining, ${ }^{129}$ and a germline mutation in $S D H B, C$, or $D$ was found in $16 \%$ of KIT/PDGFRA wild-type GIST. ${ }^{130}$ Therefore, abnormalities of mitochondrial complex 2, attributable to $S D H$ germline mutation or not, may be implicated in another oncogenic pathway than KIT/PDGFRAs. Additional studies on SDHB are necessary before use in routine practice.

\section{Germline mutations of KIT or PDGFRA}

The first family with a germline KIT mutation has been described in 1998, only a few months after the first report of activating KIT mutations in most of sporadic GISTs., ${ }^{3,131}$ Since this date, many germline KIT or PDGFRA mutations

Table 3 Germline mutations and clinical features

\begin{tabular}{|c|c|c|c|c|}
\hline $\begin{array}{l}\text { Germline } \\
\text { mutations }\end{array}$ & $\begin{array}{l}\text { No. of relatives } \\
\text { with GISTs }{ }^{a}\end{array}$ & $\begin{array}{l}\text { GIST } \\
\text { location }\end{array}$ & $\begin{array}{l}\text { Particular clinical } \\
\text { features }\end{array}$ & $\begin{array}{l}\text { Imatinib } \\
\text { response }^{b}\end{array}$ \\
\hline \multicolumn{5}{|l|}{ KIT } \\
\hline \multicolumn{5}{|l|}{ Exon II } \\
\hline W557R ${ }^{144}$ & 15 & $\mathrm{G}, \mathrm{SI}$ & $\begin{array}{l}\text { Skin hyperpigmentation, } \\
\text { dysphagia }\end{array}$ & \\
\hline V559A $135,138,142,147,148$ & 10 & G, SI & $\begin{array}{l}\text { Skin hyperpigmentation, } \\
\text { lentigines, urticaria } \\
\text { pigmentosa, nevi }\end{array}$ & $-^{c}$ \\
\hline Del559131 & 7 & $-^{c}$ & Skin hyperpigmentation & $-^{c}$ \\
\hline V560G $\mathrm{G}^{138}$ & 4 & SI & Skin hyperpigmentation & \\
\hline L576-P577 insQL ${ }^{134}$ & 3 & $\mathrm{G}, \mathrm{SI}$ & Skin hyperpigmentation & $-^{c}$ \\
\hline Q575_P577delinsH $H^{132}$ & 2 & $\mathrm{R}$ & $-^{c}$ & PR or SD \\
\hline Del579 $133,137,145$ & 27 & G, SI, C & $\begin{array}{l}\text { Skin hyperpigmentation, } \\
\text { nevi }\end{array}$ & SD \\
\hline \multicolumn{5}{|l|}{ Exon 13} \\
\hline $\mathrm{K} 642 \mathrm{E}^{140,149}$ & 3 & $\mathrm{O}, \mathrm{G}, \mathrm{SI}, \mathrm{R}$ & $\begin{array}{l}\text { Lentigines, dysphagia } \\
\text { (unpublished data) }\end{array}$ & SD \\
\hline \multicolumn{5}{|l|}{ Exon 17} \\
\hline D820Y'141,146,150 & 15 & G, SI, R & Dysphagia & PR or SD \\
\hline$N 822 Y^{136}$ & 4 & $\mathrm{G}, \mathrm{SI}$ & $-c$ & PR or SD \\
\hline \multicolumn{5}{|l|}{ PDGFRA } \\
\hline \multicolumn{5}{|l|}{ Exon 12} \\
\hline V56ID 139 & $\mathrm{I}$ & $\mathrm{G}$ & $\begin{array}{l}\text { Fibrous polyps and } \\
\text { lipomas of the small } \\
\text { intestine }\end{array}$ & $-^{c}$ \\
\hline \multicolumn{5}{|l|}{ Exon 14} \\
\hline$N 846 Y^{143}$ & 7 & G & Large hands & $-^{c}$ \\
\hline
\end{tabular}

Notes: aConfirmed or suspected by medical record or death certificate. bln all cases in patients with advanced GIST. 'Not described.

Abbreviations: GIST, gastrointestinal stromal tumors; O, esophagi; G, gastric; SI, small intestine; C, colon; R, rectum; PR, partial response; SD, stable disease. 
have been identified in rare kindreds with multiple occurrences of GIST among blood relatives. Today, 16 different germline mutations involving exons 8, 11, 13, or 17 of KIT or exons 12 or 14 of PDGFRA have been reported to our knowledge (Table 3). ${ }^{131-150}$ In all publications, the pattern of inheritance is autosomal dominant with a penetrance of almost $100 \%$. GISTs are multiple in most cases and frequently multifocal. They occurred at earlier ages than corresponding sporadic GISTs, commonly in young adults, and median age at diagnosis is approximately $40-50$ years. Some authors have suggested a possible genetic anticipation because of decreasing age at diagnosis across generations. ${ }^{141,144,150}$ However, it was not reported previously, and earlier ages at diagnosis might be only due to greater interest for GISTs and/or screening of relatives. Various clinical features have been reported in these families and are described according to activating germline mutation in Table 3. Skin lesions features appeared to be frequent (Figure 4A), in particular in cases of KIT exon 11 mutation. The molecular mechanism of their occurrence is unclear, but, interestingly, a decrease in the number of pigmented lesions has been noted in one patient treated with imatinib given an additional proof of their relationship with activating KIT mutations. ${ }^{151}$

Histologically, a diffuse proliferation of interstitial cells of Cajal is found in the myenteric plexus layer of gastrointestinal tract of affected cases (Figure 4B). This proliferation is a polyclonal hyperplasia, while GISTs are monoclonal. ${ }^{152}$ This is of particular interest because it demonstrates that activating KIT or PDGFRA mutations are necessary but not sufficient for GIST pathogenesis. Moreover, GISTs from a same patient with germline mutation are derived from independent clones and show different cytogenetic abnormalities, suggesting that different progression pathways can lead to GIST from polyclonal hyperplasia. ${ }^{150,152}$ This point is supported by analysis of cytogenetic abnormalities in sporadic GISTs. In them, losses at chromosomes 1p, 14q, and 22q are frequent and characteristic of the abnormalities. ${ }^{153}$ Three major cytogenetic pathways associated with GIST location and behaviors have been suggested from these alterations. ${ }^{154}$ Nevertheless, apart from activating mutations of KIT or PDFGRA, our understanding of fine molecular alterations implicated in GISTs pathogenesis are limited. At present, there is no recommendation for screening, follow-up, and treatment of patients harboring germline mutation. All patients will develop GISTs, but not all of these tumors will be malignant. Imatinib chemoprevention is questionable as patients may have long-term side effects, and it is not clear that there is any role for lifelong therapy. In the absence of a method allowing the determination of GIST evolution, aggressive treatment such as repeated surgery should be as limited as possible, and it is probable that only growing or large GISTs should be resected. The National Institutes of Health is currently sponsoring a research study focusing on learning more about hereditary GISTs: the Project Flag (http://www.projectflag.org/).

Three murine models of GIST harboring germline KIT mutations have been developed using expression of KIT

A

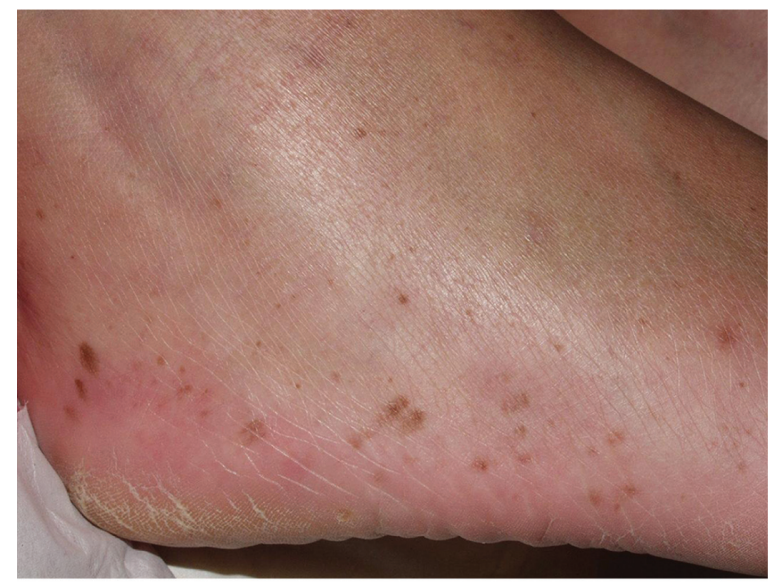

B

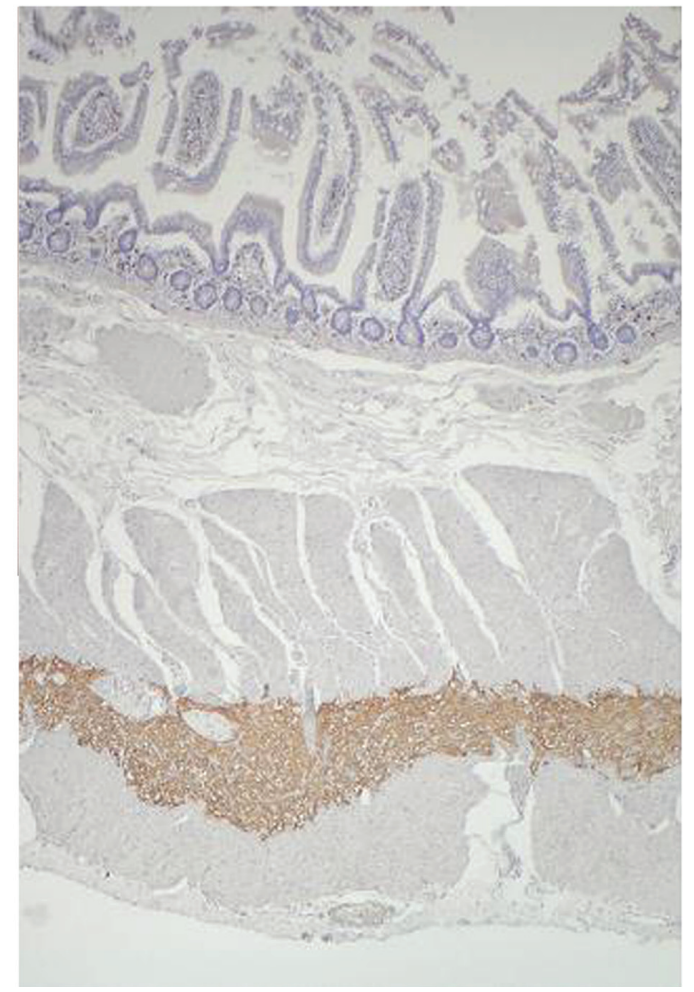

Figure 4 Clinical and histological features in patients with KIT germline mutations. A) Diffuse lentigines in a patient with KIT exon 13 germline mutation. B) Hyperplasia of interstitial cells of Cajal in the myenteric plexus layer of small intestine of the same patient. 
mutant in transgenic knock-in mice. KIT mutations used are three known human germline mutations and involved exons 11 (558delV corresponding to human 559delV), 13 (D818Y corresponding to human D820Y), or 17 (K641E corresponding to human K642E). Heterozygous and homozygous mice developed diffuse hyperplasia of interstitial cells of Cajal in the digestive tract (from esophagus to large intestine) and GIST-like cecal tumor. ${ }^{155-157}$ Homozygous mice developed larger cecal tumor and died due to gastrointestinal obstruction after some weeks. ${ }^{156,157}$ There is no clear explanation for the differences observed in GIST location between murine model and human. However, these models are promising to improve our knowledge of KIT oncogenic signaling pathways. Moreover, mouse models will be useful for the preclinical investigation of new targeted therapies and overcome secondary resistance mutations. ${ }^{158,159}$

\section{Conclusion}

GISTs receive today considerable attention because of substantial advances in the understanding of their pathogenesis and development of efficient targeted therapies. The diagnostic of this disease relies on concordant histology and KIT immunopositivity. Mutational analysis for activating KIT and PDGFRA mutations is strongly recommended in KIT-negative tumors and in all advanced GISTs. In the future, patients' treatment will probably be determined according to the predictive value of primary and/or secondary mutations. Activating mutations of KIT or PDGFRA protooncogenes are present in more than $80 \%$ of GISTs. Nevertheless, molecular analysis of GISTs occurring in patients with genetic predisposition have shown that some GISTs or GIST-like tumors are secondary to inactivating mutations of tumor suppressor genes like $S D H$ or $N F 1$.

\section{Acknowledgment}

This work was supported by grants from AROLD.

\section{Disclosure}

Jean-François Emile serves as a consultant or advisor for Novartis and receives honoraria from Novartis.

\section{References}

1. Hirota S, Isozaki K, Moriyama Y, et al. Gain-of-function mutations of c-kit in human gastrointestinal stromal tumors. Science. 1998; 279(5350):577-580.

2. Kindblom LG, Remotti HE, Aldenborg F, Meis-Kindblom JM. Gastrointestinal pacemaker cell tumor (GIPACT): gastrointestinal stromal tumors show phenotypic characteristics of the interstitial cells of cajal. Am J Pathol. 1998;152(5):1259-1269.

3. Lee HT, Hennig GW, Fleming NW, et al. The mechanism and spread of pacemaker activity through myenteric interstitial cells of cajal in human small intestine. Gastroenterology. 2007;132(5):1852-1865.
4. Heinrich MC, Corless CL, Duensing A, et al. PDGFRA activating mutations in gastrointestinal stromal tumors. Science. 2003; 299(5607): 708-710.

5. Rubin BP, Heinrich MC, Corless CL. Gastrointestinal stromal tumour. Lancet. 2007;369(9574):1731-1741.

6. Emile JF, Théou N, Tabone S, et al. Clinicopathologic, phenotypic, and genotypic characteristics of gastrointestinal mesenchymal tumors. Clin Gastroenterol Hepatol. 2004;2(7):597-605.

7. Miettinen M, Sobin LH, Lasota J. Gastrointestinal stromal tumors of the stomach. A clinicopathologic, immunohistochemical, and molecular genetic study of 1765 cases with long-term follow-up. Am J Surg Pathol. 2005;29(1):52-68.

8. Miettinen M, Makhlouf H, Sobin LH, Lasota J. Gastrointes tinal stromal tumors of the jejunum and ileum. A clinicopathologic, immunohistochemical, and molecular genetic study of 906 cases before imatinib with long-term follow-up. Am J Surg Pathol. 2006;30(4): 477-489.

9. Nilsson B, Bümming P, Meis-Kindblom JM, et al. Gastrointestinal stromal tumors: the incidence, prevalence, clinical course, and prognostication in the preimatinib mesylate era. A population-based study in western Sweden. Cancer. 2005;103(4):821-829.

10. Tryggvason G, Gislason HG, Magnusson MK, Jonasson JG. Gastrointestinal stromal tumors in Iceland, 1990-2003: the Icelandic GIST study, a population-based incidence and pathologic risk stratification study. Int J Cancer. 2005;117(2):289-293.

11. Goettsch WG, Bos SD, Breekveldt-Postma N, Casparie M, Herings RM, Hogendoorn PC. Incidence of gastrointestinal stromal tumours is underestimated: results of a nation-wide study. Eur J Cancer. 2005;41(18):2868-2872.

12. Agaimy A, Wünsch PH, Hofstaedter F, et al. Minute gastric sclerosing stromal tumors (GIST tumorlets) are common in adults and frequently show c-KIT mutations. Am J Surg Pathol. 2007;31(1):113-120.

13. Yamamoto H, Oda Y, Kawaguchi K, et al. c-kit and PDGFRA mutations in extragastrointestinal stromal tumor (gastrointestinal stromal tumor of the soft tissue). Am J Surg Pathol. 2004;28(4):479-488.

14. Burkill GJ, Badran M, Al-Muderis O, et al. Malignant gastrointestinal stromal tumor: distribution, imaging features, and pattern of metastatic spread. Radiology. 2003;226(2):527-532.

15. DeMatteo RP, Lewis JJ, Leung D, Mudan SS, Woodruff JM, Brennan MF. Two hundred gastrointestinal stromal tumors: recurrence patterns and prognostic factors for survival. Ann Surg. 2000;231(1):51-58.

16. Blay JY, Bonvalot S, Casali P, et al. Consensus meeting for the management of gastrointestinal stromal tumors. Report of the GIST Consensus Conference of 2004 Mar 20-21, under the auspices of ESMO. Ann Oncol. 2005;16(4):566-578.

17. Emory TS, Sobin LH, Lukes L, Lee DH, O'Leary TJ. Prognosis of gastrointestinal smooth-muscle (stromal) tumors: dependence on anatomic site. Am J Surg Pathol. 1999;23(1):82-87.

18. Franquemont DW. Differentiation and risk assessment of gastrointestinal stromal tumors. Am J Clin Pathol. 1995;103(1):41-47.

19. Hasegawa T, Matsuno Y, Shimoda T, Hirohashi S. Gastrointestinal stromal tumor: consistent CD117 immunostaining for diagnosis, and prognostic classification based on tumor size and MIB-1 grade. Hum Pathol. 2002;33(6):669-676.

20. Sabah M, Cummins R, Leader M, Kay E. Loss of heterozygosity of chromosome $9 \mathrm{p}$ and loss of $\mathrm{p} 16^{\mathrm{INK} 4 \mathrm{~A}}$ expression are associated with malignant gastrointestinal stromal tumors. Mod Pathol. 2004;17(11): 1364-1371.

21. Nakamura N, Yamamoto H, Yao T, et al. Prognostic significance of expressions of cell-cycle regulatory proteins in gastrointestinal stromal tumor and the relevance of the risk grade. Hum Pathol. 2005;36(7): $828-837$.

22. Imamura M, Yamamoto H, Nakamura N, et al. Prognostic significance of angiogenesis in gastrointestinal stromal tumor. Mod Pathol. 2007;20(5):529-537.

23. Fletcher CD, Berman JJ, Corless C, et al. Diagnosis of gastrointestinal stromal tumors: a consensus approach. Hum Pathol. 2002;33(5): $459-465$. 
24. Miettinen M, Lasota J. Gastrointestinal stromal tumors: pathology and prognosis at different sites. Semin Diagn Pathol. 2006;23(2): $70-83$.

25. Gold JS, Gönen M, Gutiérrez A, et al. Development and validation of a prognostic nomogram for recurrence-free survival after complete surgical resection of localised primary gastrointestinal stromal tumour: a retrospective analysis. Lancet Oncol. 2009;10(11):1045-1052.

26. Joenssu H, Roberts PJ, Sarlomo-Rikala M, et al. Effect of the tyrosine kinase inhibitor STI571 in a patient with a metastatic gastrointestinal stromal tumor. N Engl J Med. 2001;344(14):1052-1056.

27. Blanke CD, Rankin C, Demetri GD, et al. Phase III randomized, intergroup trial assessing imatinib mesylate at two dose levels in patients with unresectable or metastatic gastrointestinal stromal tumors expressing the kit receptor tyrosine kinase: S0033. J Clin Oncol. 2008;26(4):626-632.

28. Verweij J, Casali PG, Zalcberg J, et al. Progression-free survival in gastrointestinal stromal tumours with high-dose imatinib: randomised trial. Lancet. 2004;364(9440):1127-1134.

29. Blay JY, Le Cesne A, Ray-Coquard I, et al. Prospective multicentric randomized phase III study of imatinib in patients with advanced gastrointestinal stromal tumors comparing interruption versus continuation of treatment beyond 1 year: the French Sarcoma Group. J Clin Oncol. 2007;25(9):1107-1113.

30. DeMatteo RP, Maki RG, Singer S, Gonen M, Brennan MF, Antonescu CR. Results of tyrosine kinase inhibitor therapy followed by surgical resection for metastatic gastrointestinal stromal tumor. Ann Surg. 2007;245(3):347-352.

31. Gronchi A, Fiore M, Miselli F, et al. Surgery of residual disease following molecular-targeted therapy with imatinib mesylate in advanced/ metastatic GIST. Ann Surg. 2007;245(3):341-346.

32. Mussi C, Ronellenfitsch U, Jakob J, et al. Post-imatinib surgery in advanced/metastatic GIST: is it worthwhile in all patients? Ann Oncol. 2010;21(2):403-408.

33. Demetri GD, van Oosterom AT, Garrett CR, et al. Efficacy and safety of sunitinib in patients with advanced gastrointestinal stromal tumour after failure of imatinib: a randomised controlled trial. Lancet. 2006;368(9544):1329-1338.

34. George S, Blay JY, Casali PG, et al. Clinical evaluation of continuous daily dosing of sunitinib malate in patients with advanced gastrointestinal stromal tumour after imatinib failure. Eur $J$ Cancer. 2009;45(11):1959-1968.

35. Wiebe L, Kasza KE, Maki RG, et al. Activity of sorafenib (SOR) in patients (pts) with imatinib (IM) and sunitinib (SU)-resistant (RES) gastrointestinal stromal tumors (GIST): a phase II trial of the University of Chicago phase II consortium. J Clin Oncol. 2008;26(15S):10502.

36. Montemurro M, Schöffski P, Reichardt P, et al. Nilotinib in the treatment of advanced gastrointestinal stromal tumours resistant to both imatinib and sunitinib. Eur J Cancer. 2009;45(13):2293-2297.

37. Evans TRJ, Morgan JA, van den Abbeele AD, et al. Phase I dose-escalation study of the SRC and multi-kinase inhibitor BMS354825 in patients (pts) with GIST and other solid tumors. $J$ Clin Oncol. 2005;23(16S):3034.

38. DeMatteo RP, Ballman KV, Antonescu CR, et al. Adjuvant imatinib mesylate after resection of localised, primary gastrointestinal stromal tumour: a randomised, double-blind, placebo-controlled trial. Lancet. 2009;373(9669):1097-1104.

39. Casali PG, Jost L, Reichardt P, Schlemmer M, Blay JY. Gastrointestinal stromal tumors: ESMO clinical recommendations for diagnosis, treatment and follow-up. Ann Oncol. 2008;19 Suppl 2:ii35-ii38.

40. Fernandez-Esparrach G, Sendino O, Solé M, et al. Endoscopic ultrasound-guided fine-needle aspiration and trucut biopsy in the diagnosis of gastric stromal tumors: a randomized crossover study. Endoscopy. 2010;42(4):292-299.
41. Philipper M, Hollerbach S, Gabbert HE, et al. Prospective comparison of endoscopic ultrasound-guided fine-needle aspiration and surgical histology in upper gastrointestinal submucosal tumors. Endoscopy. 2010;42(4):300-305.

42. Gayed I, Vu T, Iyer R, et al. The role of 18 F-FDG PET in staging and early prediction of response to therapy of recurrent gastrointestinal stromal tumors. $J$ Nucl Med. 2004;45(1):17-21.

43. Rosenbaum SJ, Stergar H, Antoch G, Veit P, Bockisch A, Kühl H. Staging and follow-up of gastrointestinal stromal tumors with PET/CT. Abdom Imaging. 2006;31(1):25-35.

44. Stroobants S, Goeminne J, Seegers M, et al. ${ }^{18}$ FDG-Positron emission tomography for the early prediction of response in advanced soft tissue sarcoma treated with imatinib mesylate $\left(\right.$ Glivec $\left.^{\circledR}\right)$. Eur J Cancer. 2003;39(14):2012-2020.

45. Choi H, Charnsangavej C, Faria SC, et al. Correlation of computed tomography and positron emission tomography in patients with metastatic gastrointestinal stromal tumor treated at a single institution with imatinib mesylate: proposal of new computed tomography response criteria. J Clin Oncol. 2007;25(13):1753-1759.

46. Emile JF, Stock N, Corless CL, et al. Dotlike or Golgi-like KIT and PDGFRA staining in GISTs. Am J Surg Pathol. 2009;33(1):157-158.

47. Tabone-Eglinger S, Subra F, El Sayadi H, et al. KIT mutations induce intracellular retention and activation of an immature form of the KIT protein in gastrointestinal stromal tumors. Clin Cancer Res. 2008;14(8):2285-2294.

48. Sihto H, Sarlomo-Rikala M, Tynninen O, et al. KIT and platelet-derived growth factor receptor alpha tyrosine kinase gene mutations and KIT amplifications in human solid tumors. J Clin Oncol. 2005;23(1): 49-57.

49. Torres-Cabala CA, Wang WL, Trent J, et al. Correlation between KIT expression and KIT mutation in melanoma: a study of 173 cases with emphasis on the acral-lentiginous/mucosal type. Mod Pathol. 2009; 22(11):1446-1456.

50. Dow N, Giblen G, Sobin LH, Miettinen M. Gastrointestinal stromal tumors: differential diagnosis. Semin Diagn Pathol. 2006;23(2): 111-119.

51. Miettinen M, Sobin LH, Sarlomo-Rikala M. Immunohistochemical spectrum of GISTs at different sites and their differential diagnosis with a reference to CD117 (KIT). Mod Pathol. 2000;13(10):1134-1142.

52. West RB, Corless CL, Chen X, et al. The novel marker, DOG1, is expressed ubiquitously in gastrointestinal stromal tumors irrespective of KIT or PDGFRA mutation status. Am J Pathol. 2004;165(1):107-113.

53. Emile JF, Lemoine A, Bienfait N, Terrier P, Azoulay D, Debuire B. Length analysis of polymerase chain reaction products: a sensitive and reliable technique for the detection of mutations in KIT exon 11 in gastrointestinal stromal tumors. Diagn Mol Pathol. 2002;11(2):107-112.

54. Blume-Jensen P, Claesson-Welsh L, Siegbahn A, Zsebo KM, Westermark $\mathrm{B}$, Heldin $\mathrm{CH}$. Activation of the human c-kit product by ligand-induced dimerization mediates circular actin reorganization and chemotaxis. EMBO J. 1991;10(13):4121-4128.

55. Corless CL, Fletcher JA, and Heinrich MC. Biology of gastrointestinal tumors. J Clin Oncol. 2004;22(18):3813-3825.

56. Mol CD, Dougan DR, Schneider TR, et al. Structural basis for the autoinhibition and STI-571 inhibition of c-Kit tyrosine kinase. $J$ Biol Chem. 2004;279(30):31655-31663.

57. Chan PM, Ilangumaran S, La Rose J, Chakrabartty A, Rottapel R. Autoinhibition of the kit receptor tyrosine kinase by the cytosolic juxtamembrane region. Mol Cell Biol. 2003;23(9):3067-3078.

58. Kitayama H, Kanakura Y, Furitsu T, et al. Constitutively activating mutations of c-kit receptor tyrosine kinase confer factor-independent growth and tumorigenicity of factor-dependent hematopoietic cell lines. Blood. 1995;85(3):790-798.

59. Roskoski R Jr. Structure and regulation of Kit protein-tyrosine kinase - the stem cell factor receptor. Biochem Biophys Res Commun. 2005;338(3):1307-1315. 
60. Ernst SI, Hubbs AE, Przygodzki RM, Emory TS, Sobin LH, O'Leary TJ. KIT mutation portends poor prognosis in gastrointestinal stromal/smooth muscle tumors. Lab Invest. 1998;78(12):1633-1636.

61. Taniguchi M, Nishida T, Hirota S, et al. Effect of c-kit mutation on prognosis of gastrointestinal stromal tumors. Cancer Res. 1999;59(17): 4297-4300.

62. Debiec-Rychter M, Dumez H, Judson I, et al. Use of c-KIT/PDGFRA mutational analysis to predict the clinical response to imatinib in patients with advanced gastrointestinal stromal tumours entered on phase I and II studies of the EORTC Soft Tissue and Bone Sarcoma Group. Eur J Cancer. 2004;40(5):689-695.

63. Penzel R, Aulmann S, Moock M, Schwarzbach M, Rieker RJ, Mechtersheimer G. The location of KIT and PDGFRA gene mutations in gastrointestinal stromal tumors is site and phenotype associated. JClin Pathol. 2005;58(6):634-639.

64. Martin J, Poveda A, Llombart-Bosch A, et al. Deletions affecting codons $557-558$ of the c-KIT gene indicate a poor prognosis in patients with completely resected gastrointestinal stromal tumors: a study by the Spanish Group for Sarcoma Research (GEIS). J Clin Oncol. 2005;23(25):6190-6198.

65. Wardelmann E, Hrychyk A, Merkelbach-Bruse S, et al. Association of platelet-derived growth factor receptor alpha mutations with gastric primary site and epithelioid or mixed cell morphology in gastrointestinal stromal tumors. J Mol Diagn. 2004;6(3):197-204.

66. Debiec-Rychter M, Sciot R, Le Cesne A, et al. KIT mutations and dose selection for imatinib in patients with advanced gastrointestinal stromal tumours. Eur J Cancer. 2006;42(8):1093-1103.

67. Andersson J, Bümming P, Meis-Kindblom JM, et al. Gastrointestinal stromal tumors with exon 11 deletions are associated with poor prognosis. Gastroenterology. 2006;130(6):1573-1581.

68. DeMatteo RP, Gold JS, Saran L, et al. Tumor mitotic rate, size, and location independently predict recurrence after resection of primary gastrointestinal stromal tumor (GIST). Cancer. 2008;112(3):608-615.

69. Emile JF, Tabone-Eglinger S, Théou-Anton N, Lemoine A. Prognostic value of KIT exon 11 deletions in GISTs. Gastroenterology. 2006;131(3):976-977.

70. Corless CL, Schroeder A, Griffith D, et al. PDGFRA mutations in gastrointestinal stromal tumors: frequency, spectrum and in vitro sensitivity to imatinib. J Clin Oncol. 2005;23(23):5357-5364.

71. Lasota J, vel Dobosz AJ, Wasag B, et al. Presence of homozygous KIT exon 11 mutations is strongly associated with malignant clinical behavior in gastrointestinal stromal tumors. Lab Invest. 2007;87(10): 1029-1041.

72. Crosier PS, Ricciardi ST, Hall LR, Vitas MR, Clark SC, Crosier KE. Expression of isoforms of the human receptor tyrosine kinase c-kit in leukemic cell lines and acute myeloid leukemia. Blood. 1993;82(4):1151-1158.

73. Caruana G, Cambareri AC, Ashman LK. Isoforms of c-KIT differ in activation of signalling pathways and transformation of NIH3T3 fibroblasts. Oncogene. 1999;18(40):5573-5581.

74. Théou N, Tabone S, Saffroy R, et al. High expression of both mutant and wild-type alleles of c-kit in gastrointestinal stromal tumors. Biochim Biophys Acta. 2004;1688(3):250-256.

75. Tabone S, Théou N, Wozniak A, et al. KIT overexpression and amplification in gastrointestinal stromal tumors (GISTs). Biochim Biophys Acta. 2005;1741(1-2):65-72.

76. Théou-Anton N, Tabone S, Brouty-Boyé D, et al. Co expression of SCF and KIT in gastrointestinal stromal tumours (GISTs) suggests an autocrine/paracrine mechanism. Br J Cancer. 2006;94(8): 1180-1185.

77. Duensing A, Medeiros F, McConarty B, et al. Mechanisms of oncogenic KIT signal transduction in primary gastrointestinal stromal tumors (GISTs). Oncogene. 2004;23(22):3999-4006.

78. Lux ML, Rubin BP, Biase TL, et al. KIT extracellular and kinase domain mutations in gastrointestinal stromal tumors. Am J Pathol. 2000;156(3):791-795.
79. Rubin BP, Singer S, Tsao C, et al. KIT activation is a ubiquitous feature of gastrointestinal stromal tumors. Cancer Res. 2001;61(22): $8118-8121$.

80. Xiang Z, Kreisel F, Cain J, Colson A, Tomasson MH. Neoplasia driven mutant c-KIT is mediated by intracellular, not plasma membrane, receptor signaling. Mol Cell Biol. 2007;27(1):267-82.

81. Emile JF, Bachet JB, Tabone-Eglinger S, Terrier P, Vignault JM. GIST with homozygous KIT exon 11 mutations. Lab Invest. 2008;88(5): 456-457.

82. Hornick JL, Fletcher CD. The role of KIT in the management of patients with gastrointestinal stromal tumors. Human Pathol. 2007;38(5):679-687.

83. Lasota J, Dansonka-Mieszkowska A, Sobin LH, Miettinen M. A great majority of GISTs with PDGFRA mutations represent gastric tumors of low or no malignant potential. Lab Invest. 2004;84(7): 874-883.

84. Bachet JB, Hostein I, Le Cesne A, et al. Prognosis and predictive value of KIT exon 11 deletion in GISTs. Br J Cancer. 2009;101(1):7-11.

85. Wardelmann E, Losen I, Hans V, et al. Deletion of Tryp-557 and Lys-558 in the juxtamembrane domain of the c-kit protooncogene is associated with metastatic behavior of gastrointestinal stromal tumors. Int J Cancer. 2003;106(6):887-895.

86. Heinrich MC, Corless CL, Demetri GD, et al. Kinase mutations and imatinib response in patients with metastatic gastrointestinal stromal tumor. J Clin Oncol. 2003;21(23):4342-4349.

87. Gastrointestinal Stromal Tumor Meta-Analysis Group (MetaGIST). Comparison of two doses of imatinib for the treatment of unresectable or metastastic gastrointestinal stromal tumors: a meta-analysis of 1640 patients. J Clin Oncol. 2010;28(7):1247-1253.

88. Dewaele B, Wasag B, Cools J, et al. Activity of dasatinib, a dual SRC/ ABL kinase inhibitor, and IPI-504, a heat shock protein 90 inhibitor, against gastrointestinal stromal tumor-associated PDGFRAD842V mutation. Clin Cancer Res. 2008;14(18):5748-5758.

89. Miselli FC, Casieri P, Negri T, et al. c-KIT/PDGFRA gene status alterations possibly related to primary imatinib resistance in gastrointestinal stromal tumors. Clin Cancer Res. 2007;13(8):2369-2377.

90. Debiec-Rychter M, Cools J, Dumez H, et al. Mechanisms of resistance to imatinib mesylate in gastrointestinal stromal tumors and activity of the PKC412 inhibitor against imatinib-resistant mutants. Gastroenterology. 2005;128(2):270-279.

91. Mahadevan D, Cooke L, Riley C, et al. A novel tyrosine kinase switch is a mechanism of imatinib resistance in gastrointestinal stromal tumors. Oncogene. 2007;26(27):3909-3919.

92. Théou N, Gil S, Devocelle A, et al. Multidrug resistance proteins in gastrointestinal stromal tumors: site-dependent expression and initial response to imatinib. Clin Cancer Res. 2005;11(21):7593-7598.

93. Chen LL, Trent JC, Wu EF, et al. A missense mutation in KIT kinase domain 1 correlates with imatinib resistance in gastrointestinal stromal tumors. Cancer Res. 2004;64(17):5913-5919.

94. Antonescu CR, Besmer P, Guo T, et al. Acquired resistance to imatinib in gastrointestinal stromal tumor occurs through secondary gene mutation. Clin Cancer Res. 2005;11(11):4182-4190.

95. Heinrich MC, Corless CL, Blanke CD, et al. Molecular correlates of imatinib resistance in gastrointestinal stromal tumors. J Clin Oncol. 2006;24(29):4764-4774.

96. Gramza AW, Corless CL, Heinrich MC. Resistance to tyrosine kinase inhibitors in gastrointestinal stromal tumors. Clin Cancer Res. 2009;15(24):7510-7518.

97. Desai J, Shankar S, Heinrich MC, et al. Clonal evolution of resistance to imatinib in patients with metastatic gastrointestinal stromal tumors. Clin Cancer Res. 2007;13(18 Pt 1):5398-5405.

98. Liegl B, Kepten I, Le C, et al. Heterogeneity of kinase inhibitor resistance mechanisms in GIST. J Pathol. 2008;216(1):64-74.

99. Negri T, Pavan GM, Virdis E, et al. T670X KIT mutations in gastrointestinal stromal tumors: making sense of missense. J Natl Cancer Inst. 2009;101(3):194-204. 
100. Roberts KG, Odell AF, Byrnes EM, et al. Resistance to c-KIT kinase inhibitors conferred by V654A mutation. Mol Cancer Ther. 2007;6(3):1159-1166.

101. Shankar S, vanSonnenberg E, Desai J, Dipiro PJ, van Den Abbeele A, Demetri GD. Gastrointestinal stromal tumor: new nodule-within-amass pattern of recurrence after partial response to imatinib mesylate. Radiology. 2005;235(3):892-898.

102. Heinrich MC, Owzar K, Corlesss CL, et al. Correlation of kinase genotype and clinical outcome in the North American Intergroup Phase III trial of imatinib mesylate for treatment of advanced gastrointestinal stromal tumor: CALGB 150105 Study by Cancer and Leukemia Group B and Southwest Oncology Group. J Clin Oncol. 2008;26(33):5360-5367.

103. Zöller ME, Rembeck B, Oden A, Samuelsson M, Angervall L. Malignant and benign tumors in patients with neurofibromatosis type 1 in a defined Swedish population. Cancer. 1997;79(11):2125-2131.

104. Friedman JM. Epidemiology of neurofibromatosis type 1. Am J Med Genet. 1999;89(1):1-6.

105. Martin GA, Viskochil D, Bollag G, et al. The GAP-related domain of the neurofibromatosis type 1 gene product interacts with ras p 21 . Cell. 1990;63(4):843-849.

106. Li Y, Bollag G, Clark R, et al. Somatic mutations in the neurofibromatosis 1 gene in human tumors. Cell. 1992;69(2):275-281.

107. Neurofibromatosis. Conference statement. National Institutes of Health Consensus Development Conference. Arch Neurol. 1988;45(5):575-578.

108. Lee MJ, Stephenson DA. Recent developments in neurofibromatosis type 1. Curr Opin Neurol. 2007;20(2):135-141.

109. Opocher G, Conton P, Schiavi F, Macino B, Mantero F. Pheochromocytoma in von Hippel-Lindau disease and neurofibromatosis type 1. Fam Cancer. 2005;4(1):13-16.

110. Takazawa Y, Sakurai S, Sakuma Y, et al. Gastrointestinal stromal tumors of neurofibromatosis type I (von Recklinhausen's disease). Am J Surg Pathol. 2005;29(6):755-763.

111. Andersson J, Sihto H, Meis-Kindblom JM, Joensuu H, Nupponen N, Kindblom LG. NF1-associated gastrointestinal stromal tumors have unique clinical, phenotypic, and genotypic characteristics. Am J Surg Pathol. 2005;29(9):1170-1176.

112. Miettinen M, Fetsch JF, Sobin LH, Lasota J. Gastrointestinal stromal tumors in patients with neurofibromatosis 1: a clinicopathologic and molecular genetic study of 45 cases. Am J Surg Pathol. 2006;30(1): 90-96.

113. Maertens O, Prenen H, Debiec-Rychter M, et al. Molecular pathogenesis of multiple gastrointestinal stromal tumors in NF1 patients. Hum Mol Genet. 2006;15(6):1015-1023.

114. Yamamoto H, Tobo T, Nakamori M, et al. Neurofibromatosis type 1-related gastrointestinal stromal tumors: a special reference to loss of heterozygosity at 14q and 22q. J Cancer Res Clin Oncol. 2009;135(6): 791-798.

115. Stewart DR, Corless CL, Rubin BP, et al. Mitotic recombination as evidence of alternative pathogenesis of gastrointestinal stromal tumours in neurofibromatosis type 1. J Med Genet. 2007;44(1):e61.

116. Carney JA, Sheps SG, Go VL, Gordon H. The triad of gastric leiomyosarcoma, functioning extra-adrenal paraganglioma and pulmonary chondroma. N Engl J Med. 1977;296(26):1517-1518.

117. Horenstein MG, Hitchcock TA, Tucker JA. Dual CD117 expression in gastrointestinal stromal tumor (GIST) and paraganglioma of Carney triad: a case report. Int J Surg Pathol. 2005;13(1):87-92.

118. Carney JA. Gastric stromal sarcoma, pulmonary chondroma, and extra-adrenal paraganglioma (Carney triad): natural history, adrenocortical component and possible familial occurrence. Mayo Clin Proc. 1999;74(6):543-552.

119. Zhang L, Smyrk TC, Young WF Jr, Stratakis CA, Carney JA. Gastric stromal tumors in Carney triad are different clinically, pathologically, and behaviorally from sporadic gastric gastrointestinal stromal tumors: findings in 104 cases. Am J Surg Pathol. 2010;34(1):53-64.

120. Stratakis CA, Carney JA. The triad of paragangliomas, gastric stromal tumours and pulmonary chondromas (Carney triad), and the dyad of paragangliomas and gastric stromal sarcomas (Carney-Stratakis syndrome): molecular genetics and clinical implications. J Int Med. 2009;266(1):43-52.
121. Carney JA, Stratakis CA. Familial paraganglioma and gastric stromal sarcoma: a new syndrome distinct from the Carney triad. Am J Med Genet. 2002;108(2):132-139.

122. Pasini B, McWhinney SR, Bei T, et al. Clinical and molecular genetics of patients with the Carney-Stratakis syndrome and germline mutations of the genes coding for the succinate dehydrogenase subunits $S D H B$, SDHC, and SDHD. Eur J Hum Genet. 2008;16(1):79-88.

123. Amar L, Bertherat J, Baudin E, et al. Genetic testing in pheochromocytoma or functional paraganglioma. J Clin Oncol. 2005;23(24): 8812-8818.

124. Miettinen M, Lasota J, Sobin LH. Gastrointestinal stromal tumors of the stomach in children and young adults: a clinicopathologic, imunohistochemical, and molecular genetic study of 44 cases with long-term follow-up and review of the literature. Am J Surg Pathol. 2005;29(10):1373-1381.

125. Prakash S, Sarran L, Socci N, et al. Gastrointestinal stromal tumors in children and young adults: a clinicopathologic, molecular, and genomic study of 15 cases and review of the literature. J Pediatr Hematol Oncol. 2005;27(4):179-187.

126. Agaram NP, Laquaglia MP, Ustun B, et al. Molecular characterization of pediatric gastrointestinal stromal tumors. Clin Cancer Res. 2008; 14(10):3204-3215.

127. van Nederveen FH, Gaal J, Favrier J, et al. An immunohistochemical procedure to detect patients with paraganglioma and phaeochromocytoma with germline SDHB, SDHC or SDHD gene mutations: a retrospective and prospective analysis. Lancet Oncol. 2009;10(8): 764-771.

128. Gill AJ, Benn DE, Chou A, et al. Immunohistochemistry for SDHB triages genetic testing of SDHB, SDHC and SDHD in paragangliomaphaeochromocytoma syndromes. Hum Pathol. 2010;41(6):805-814.

129. Gill AJ, Chou A, Vilain R, et al. Immunohistochemistry for SDHB divides gastrointestinal stromal tumors (GISTs) into 2 distinct types. Am J Surg Pathol. 2010;34(5):636-644.

130. Janeway KA, Kim S, Lodish M, et al. Succinate dehydrogenase in KIT/ PDGFRA wild-type gastrointestinal stromal tumors. J Clin Oncol. 2010;28(15S):A10008.

131. Nishida T, Hirota S, Taniguchi M, et al. Familial gastrointestinal stromal tumours with germline mutation of the KIT gene. Nat Genet. 1998;19(4):323-324.

132. Wozniak A, Rutkowski P, Sciot R, Ruka W, Michej W, DebiecRychter M. Rectal gastrointestinal stromal tumors associated with a novel germline KIT mutation. Int J Cancer. 2008;122(9):2160-2164.

133. Lasota J, Miettinen M. A new familial GIST identified. Am J Surg Pathol. 2006;30(10):1342.

134. Carballo M, Roig I, Aguilar F, et al. Novel c-KIT germline mutation in a family with gastrointestinal stromal tumors and cutaneous hyperpigmentation. Am J Med Genet A. 2005;132(4):361-364.

135. Li FP, Fletcher JA, Heinrich MC, et al. Familial gastrointestinal stromal tumor syndrome: phenotypic and molecular features in a kindred. $J$ Clin Oncol. 2005;23(12):2735-2743.

136. Thalheimer A, Schlemmer M, Bueter M, et al. Familial gastrointestinal stromal tumors caused by the novel KIT exon 17 germline mutation N822Y. Am J Surg Pathol. 2008;32(10):1560-1565.

137. Kleinbaum EP, Lazar AJ, Tamborini E, et al. Clinical, histopathologic, molecular and therapeutic findings in a large kindred with gastrointestinal stromal tumor. Int J Cancer. 2008;122(3):711-718.

138. Kang DY, Park CK, Choi JS, et al. Multiple gastrointestinal stromal tumors: clinicopathologic and genetic analysis of 12 patients. $\mathrm{Am} \mathrm{J}$ Surg Pathol. 2007;31(2):224-232.

139. Pasini B, Matyakhina L, Bei T, et al. Multiple gastrointestinal stromal and other tumors caused by platelet-derived growth factor receptor alpha gene mutations: a case associated with a germline V561D defect. J Clin Endocrinol Metab. 2007;92(9):3728-3732.

140. Graham J, Debiec-Rychter M, Corless CL, Reid R, Davidson R, White $\mathrm{R}$. Imatinib in the management of multiple gastrointestinal stromal tumors associated with a germline KIT K642E mutation. Arch Pathol Lab Med. 2007;131(9):1393-1396.

141. O'Riain C, Corless CL, Heinrich MC, et al. Gastrointestinal stromal tumors: insights from a new familial GIST kindred with unusual genetic and pathologic features. Am J Surg Pathol. 2005;29(12):1680-1683. 
142. Kim HJ, Lim SJ, Park K, Yuh YJ, Jang SJ, Choi J. Multiple gastrointestinal stromal tumors with a germline c-kit mutation. Pathol Int. 2005;55(10):655-659.

143. Chompret A, Kannengiesser C, Barrois M, et al. PDGFRA germline mutation in a family with multiple cases of gastrointestinal stromal tumor. Gastroenterology. 2004;126(1):318-321.

144. Robson ME, Glogowski E, Sommer G, et al. Pleomorphic characteristics of a germ-line KIT mutation in a large kindred with gastrointestinal stromal tumors, hyperpigmentation, and dysphagia Clin Cancer Res. 2004;10(4):1250-1254.

145. Tarn C, Merkel E, Canutescu AA, et al. Analysis of KIT mutations in sporadic and familial gastrointestinal stromal tumors: therapeutic implications through protein modeling. Clin Cancer Res. 2005;11(10):3668-3677.

146. Hirota S, Nishida T, Isozaki K, et al. Familial gastrointestinal stromal tumors associated with dysphagia and novel type germline mutation of KIT gene. Gastroenterology. 2002;122(5):1493-1499.

147. Maeyama H, Hidaka E, Ota H, et al. Familial gastrointestinal stromal tumor with hyperpigmentation: association with a germline mutation of the c-kit gene. Gastroenterology. 2001;120(1):210-215.

148. Beghini A, Tibiletti MG, Roversi G, et al. Germline mutation in the juxtamembrane domain of the kit gene in a family with gastrointestinal stromal tumors and urticaria pigmentosa. Cancer. 2001;92(3): $657-662$.

149. Isozaki K, Terris B, Belghiti J, Schiffmann S, Hirota S, Vanderwinden JM. Germline-activating mutation in the kinase domain of KIT gene in familial gastrointestinal stromal tumors. Am J Pathol. 2000;157(5):1581-1585.

150. Veiga I, Silva M, Vieira J, et al. Hereditary gastrointestinal stromal tumors sharing the KIT exon 17 germline mutation p. Asp820Tyr develop through different cytogenetic pathways. Genes Chromosomes Cancer. 2010;49(2):91-98.
151. Campbell T, Felsten L, Moore J. Disappearance of lentigines in a patient receiving imatinib treatment for familial gastrointestinal stromal tumor syndrome. Arch Dermatol. 2009;145(11):1313-1316.

152. Chen H, Hirota S, Isozaki K, et al. Polyclonal nature of diffuse proliferation of interstitial cells of Cajal in patients with familial and multiple gastrointestinal stromal tumours. Gut. 2002;51(6): 793-796.

153. Chen Y, Tzeng CC, Liou CP, Chang MY, Li CF, Lin CN. Biological significance of chromosomal imbalance aberrations in gastrointestinal stromal tumors. J Biomed Sci. 2004;11(1):65-71.

154. Gunawan B, von Heydebreck A, Sander B, et al. An oncogenetic tree model in gastrointestinal stromal tumours (GISTs) identifies different pathways of cytogenetic evolution with prognostic implications. J Pathol. 2007;211(4):463-470.

155. Sommer G, Agosti V, Ehlers I, et al. Gastrointestinal stromal tumors in a mouse by targeted mutation of the Kit receptor tyrosine kinase. Proc Natl Acad Sci U S A. 2003;100(11):6706-6711.

156. Rubin BP, Antonescu CR, Scott-Browne JP, et al. A knock-in mouse model of gastrointestinal tumor harboring KIT K641E. Cancer Res. 2005;65(15):6631-6639.

157. Nakai N, Ishikawa T, Nishitani A, et al. A mouse model of a human multiple GIST family with KIT-Asp820Tyr mutation generated by a knock-in strategy. J Pathol. 2008;214(3):302-311.

158. Ishikawa $\mathrm{T}$, Nakai $\mathrm{N}$, Liu NN, et al. In vivo effect of imatinib on progression of cecal GIST-like tumors in exon 17-type c-kit kock-in mice. Lab Invest. 2009;89(10):1161-1168.

159. Rossi F, Ehlers I, Agosti V, et al. Oncogenic Kit signaling and therapeutic intervention in a mouse model of gastrointestinal stromal tumor Proc Natl Acad Sci U SA. 2006;103(34):12843-12848.
The Application of Clinical Genetics

\section{Publish your work in this journal}

The Application of Clinical Genetics is an international, peer-reviewed open access journal that welcomes laboratory and clinical findings in the field of human genetics. Specific topics include: Population genetics; Functional genetics; Natural history of genetic disease; Managemen of genetic disease; Mechanisms of genetic disease; Counselling and

\section{Dovepress}

ethical issues; Animal models; Pharmacogenetics; Prenatal diagnosis; Dysmorphology. The manuscript management system is completely online and includes a very quick and fair peer-review system, which is all easy to use. Visit http://www.dovepress.com/testimonials.php to read real quotes from published authors. 